\title{
Short-term Ketogenic Diet Induces a Molecular Response that is Distinct from Dietary Protein Restriction
}

$1 \quad$ Krystle C. Kalafut ${ }^{1}$, Sarah J. Mitchell², Michael R. MacArthur ${ }^{2 *}$, James R. Mitchell ${ }^{2,3}$

$2 \quad{ }^{1}$ Harvard T.H. Chan School of Public Health, Department of Molecular Metabolism, Boston, MA,

3 USA

$4 \quad{ }^{2}$ Department of Health Sciences and Technology, Swiss Federal Institute of Technology (ETH)

5 Zurich, Zurich, Switzerland

$6 \quad{ }^{3}$ Deceased

7 * Correspondence and Lead Contact:

8 Michael R. MacArthur, Ph.D.

9 Postdoctoral Fellow

10 ETH Zurich

11 SLA Schorenstrasse 16

12 CH-8603 Schwerzenbach Switzerland

13 mmacarthur@ethz.ch

14 Keywords: ketogenic, dietary restriction, protein restriction, carbohydrate, protein, FGF21 


\section{Restriction}

\section{Abstract}

There is increasing interest in utilizing short-term dietary interventions in the contexts of cancer, surgical stress and metabolic disease. These short-term diets may be more feasible than extended interventions and may be designed to complement existing therapies. In particular, the high-fat, lowcarbohydrate ketogenic diet $(\mathrm{KD})$, traditionally used to treat epilepsy, has gained popularity as a potential strategy for weight loss and improved metabolic health. In mice, long-term KD improves insulin sensitivity and extends lifespan and healthspan. Dietary protein restriction (PR) causes increased energy expenditure, weight loss and improved glucose homeostasis. Since KD is inherently a low-protein diet (10\% of calories from protein vs. $20 \%$ in control diet), here we evaluated the potential for mechanistic overlap between PR and KD via activation of a PR response. Mice were fed control, protein-free, or one of four ketogenic diets with varying protein content for 8 days. PF and KD diets both decreased body weight, fat mass, and liver weights, and reduced fasting glucose and insulin levels, compared to mice fed the control diet. However, PF and KD differed with respect to insulin tolerance and hepatic insulin sensitivity, which were increased in PF-fed mice and impaired in KD-fed mice relative to controls. Furthermore, contrary to the PF-fed mice, mice fed ketogenic diets containing at least $5 \%$ protein did not increase hepatic $F g f 21$ or brown adipose Ucpl expression. Interestingly, mice fed KD lacking protein demonstrated greater elevations in hepatic $F g f 21$ than mice fed a low-fat $\mathrm{PF}$ diet. To further elucidate potential mechanistic differences between PF and KD diets and the interplay between dietary protein and carbohydrate restriction, we conducted RNA-seq analysis on livers from mice fed each of the six diets and identified distinct gene sets which respond to dietary protein content, dietary fat content, and ketogenesis. We conclude that KD with $10 \%$ of energy from protein does not induce a protein restriction response, and that the overlapping metabolic benefits of $\mathrm{KD}$ and $\mathrm{PF}$ diets occur via distinct underlying mechanisms. 


\section{Restriction}

\section{Introduction}

66 The ability of dietary interventions to improve metabolic health and stress resistance has been

67 extensively demonstrated in animal models since the first studies on caloric restriction in the early 68 1900's (1-3). Many recent studies have focused on dietary restriction of specific macronutrients, which 69 in some cases has been shown to have similar benefits as total caloric restriction. Both the high-fat, low-carbohydrate ketogenic diet (KD) and protein restricted (PR) diets improve metabolic health and stress resistance in mice (4-7). However, whether there is an overlapping mechanism that underlies the benefits of these diets remains to be determined.

Long-term feeding of both KD and PR diets improves metabolic health in mice. PR diets with a low protein-to-carbohydrate ratio improve measures of cardiometabolic health and glucose tolerance in mice and are associated with lower body weight, and reduced plasma lipids and insulin (8-10). Similarly, long-term KD reduces body weight gain and improves insulin and glucose tolerance in mice when started early in life (11). Although the metabolic phenotypes of extended KD and PR interventions are similar, studies evaluating short-term KD $(\leq 5$ weeks) found impaired hepatic insulin resistance, despite significantly reduced plasma glucose and insulin (12-14). This contrasts with PR diets which show profound improvements in glucose and lipid homeostasis after just 7 days (15).

Clinically, both KD and PR have a history of long-term use in the treatment of idiopathic epilepsy in adults and children (16-21) and renal failure (22-26), respectively. In addition to effectively treating these conditions, both dietary interventions were observed to improve cardiometabolic parameters in human patients. KD has been shown to cause significant weight loss and reduction in cardiovascular risk factors, including blood pressure, and serum triglycerides and insulin, in non-epileptic humans with obesity (27). PR has been shown to substantially improve glucose and insulin homeostasis in humans with and without diabetes (28-31). In addition, high protein intake is associated with increased overall mortality and mortality from cancer or diabetes in individuals under the age of 65 (32).

Recently, the therapeutic value of short-term or cyclic KD and PR are being investigated for a variety of indications aside from epilepsy and renal insufficiency. Studies in mice have demonstrated that 10 days of KD-feeding can improve the efficacy of PI3K inhibitors in xenograft models (33), and shortterm KD was recently shown to impact xenograft tumor growth through alterations in metabolic signaling and nutrient availability (34). Previous pilot studies have demonstrated that KD is safe and feasible in patients with glioblastoma and other advanced cancers (35-37), and there is an ongoing pilot study to evaluate the tolerability of KD in endometrial cancer patients (NCT03285152). Short-term $\mathrm{KD}$ has also been proposed to protect against adipose tissue inflammation in mice (38). In addition, a recent report showed that one-week cycles of $\mathrm{KD}$ alternated with a control diet reduces midlife mortality and improves measures of healthspan and memory in mice (39). The fasting mimicking diet (FMD) combines calorie restriction and PR and is being tested as an adjunct to chemotherapy in multiple cancer types $(40,41)$. Short 4 - or 5-day cycles of FMD have also been shown to improve measures of cardiometabolic health in humans (42), and to improve late-life health, included delayed cancer incidence, in mice (43). Preconditioning with short-term PR also effectively protects against ischemic surgical stress in mouse models $(4,44)$ and a combination of calorie restriction and PR has been shown to be safe in humans prior to surgery $(45,46)$. Given the recent clinical interest in shorterterm KD and PR diets, it is important to understand the mechanism by which these interventions improve health and stress resistance to fully harness their therapeutic potential.

107 Both KD and PR are known to induce numerous metabolic adaptations that may contribute to the 108 observed benefits. PR is associated with increases in energy expenditure and thermogenesis, as well as 


\section{Restriction}

109 increased circulating FGF21, a hormone that regulates energy balance by acting on various tissues (47110 50). KD is associated with improvements in lipid homeostasis, including upregulation of fatty acid 111 oxidation and fat utilization and decreased lipid synthesis $(14,51)$. Interestingly, clinical KD diets used 112 in humans are also restricted in protein content, with 5-10\% of calories coming from protein compared 113 to $15-20 \%$ in normal diets. This raises the question of whether overlapping molecular mechanisms 114 related to reduced dietary protein content underlie the improvements in metabolic health and longevity 115 in response to KD and PR.

116 The goal of this study was to compare the molecular signatures of mice fed KD to those of mice fed a 117 protein-free (PF) diet. In addition to comparing low-protein/high carbohydrate (PF) to high fat/low 118 carbohydrate ketogenic diet (KD), the protein content of KD was further titrated between 0-10\% to evaluate the contribution of dietary protein to the KD phenotypes. After 1 week, PF and KD diets both decreased body weight, fat mass, and liver weights, and reduced fasting glucose and insulin levels, compared to mice fed the control diet. Contrary to the PF-fed mice, KD-fed mice did not increase markers of the physiological response to protein restriction, including hepatic Fgf2l or BAT Ucpl expression. PF and KD also differed with respect to glucose and insulin tolerance and hepatic insulin signaling potential, which were all increased in PF-fed mice and impaired in KD-fed mice relative to controls. The intermediate diets revealed that increasing the protein content of the KD diet to $20 \%$ of energy impairs ketogenesis, as has been previously reported, but that replacing the protein in KD with carbohydrate does not. Liver transcriptomics further illuminated potential shared and independent mechanisms underlying the metabolic adaptations to carbohydrate and protein restriction, including shared alterations in fatty acid metabolism, but distinct changes in amino acid metabolism in PR and nucleotide metabolism in KD. We conclude that KD does not induce a robust protein restriction response, and that the overlapping metabolic benefits of KD and PF diets may be explained by distinct underlying mechanisms.

\section{Methods}

\section{$135 \quad 2.1$ Mice}

136 16-week-old male B6D2/F1 hybrid mice were purchased from Jackson Labs (strain no. 100006). Mice 137 were acclimated to the Harvard T.H. Chan School of Public Health mouse facility for two weeks prior 138 to experiments and were fed a standard chow diet during this acclimation period (Purina, 5053-PicoLab Rodent Diet 20). Mice were allowed ad libitum access to food and water unless otherwise noted. Mouse numbers were $n=4$ per diet group for the GTT, ITT, and insulin injection experiments, and a separate cohort of $n=6$ per diet group for all other analyses, with 2 mice co-housed per cage. Mice were maintained at $22^{\circ} \mathrm{C}$ with 12-hour light-dark cycles and 30-50\% relative humidity. Mice were housed in a Specific Pathogen Free (SPF) facility, as determined by screening of sentinel animals at monthly intervals. Mice were fasted for six hours prior to sacrifice and tissue collection. All procedures were approved by the Harvard Institutional Animal Care and Use Committee.

147 Semi-purified diets were prepared using combinations of soluble protein-free base mixtures 148 D12450Spx or D100070801Lpx (Research Diets, Tables S1-2), cocoa butter, casein, cystine and 149 sucrose (Fig. S1B). Mixtures were combined with an equal mass of $2 \%$ agar in water to form a solid 


\section{Restriction}

150 gel diet. Diets had macronutrient compositions and energy densities as listed in Supplemental Figure 151 S1A. Food intake was measured daily at approximately ZT10.

\section{$152 \quad 2.3$ Body Composition}

153 Body mass was determined by daily measurement at approximately ZT10. Lean and fat mass were 154 measured in awake mice using an EchoMRI analyzer system.

\section{$155 \quad 2.4$ Serum Measurements}

156 Mice were fasted for 6 hours prior to measurements and tail vein blood collection. Glucose was 157 measured using a Clarity BG1000 handheld glucometer. Serum insulin was measured by ELISA 158 following manufacturer protocol (Crystal Chem, \#90080). Ketones were measured using a Nova Max Plus Glucose/Ketone handheld meter with Nova Max Ketone Strips. Serum FGF21 was measured by ELISA following manufacturer protocol (R\&D Systems, \#MF2100).

\subsection{Glucose and Insulin Tolerance Tests}

162 Metabolic assessments were performed in a separate cohort of mice fed either CTL, PF, or KD10P 163 diets ( $n=4$ per diet). An oral glucose tolerance test (OGTT) was performed on day 6 and an insulin 164 tolerance test (ITT) was performed on day 8. For OGTT, mice were fasted for 6 hours and then 30\% 165 D-glucose (Sigma Aldrich) in sterile water was administered by oral gavage at $2 \mathrm{~g} / \mathrm{kg}$. Blood glucose was measured from a small tail nick prior to (time 0) and at 15-, 30-, 60- and 120-minutes postgavage using a handheld glucometer (Clarity BG1000). Blood was collected via tail vein at all timepoints, and serum was generated for insulin measurement.

For ITT, mice were fasted for 4 hours then injected intraperitoneally with $1.5 \mathrm{IU} / \mathrm{kg}$. Blood glucose was measured from a small tail nick prior to (time 0) and at 15-, 30-, 60- and 120-minutes post-

171 injection as above.

\section{$172 \quad 2.6$ Insulin Signaling}

173 Mice fed CTL, PF, or KD10P diets for 10 days ( $n=4$ per group) were fasted for 6 hours and then 174 injected with $1.5 \mathrm{IU} / \mathrm{kg}$ insulin or vehicle for 20 minutes. Liver tissue was collected and flash frozen 175 prior to analysis.

\subsection{Immunoblotting}

177 Flash-frozen liver tissue was homogenized and lysed in RIPA buffer (50mM Tris-Cl pH 7.4, 150mM $178 \mathrm{NaCl}, 1 \%$ IGEPAL, 0.5\% sodium deoxycholic acid, 0.1\% SDS, 1mM EDTA, 10mM NaF, 10mM 179 sodium pyrophosphate, $1 \mathrm{mM} \beta$-glycerophosphate, and $1 \mathrm{mM}$ sodium orthovanadate, Sigma protease 180 inhibitor P8340). Protein quantification was performed using a BCA assay kit (Thermo Scientific) and equal amounts of protein were separated by SDS-PAGE, transferred to nitrocellulose membranes, and immunoblotted with indicated primary antibodies. Primary antibodies: p-IRS1 (CST, 2381), IRS (CST, 2382), p-FoxO1 (CST, 9464), FoxO1 (CST, 9462), p-Akt (CST, 4060), Akt (CST, 4691), p-rpS6 S235/36 (CST, 2211), rpS6 (CST, 2217), and Actin (CST, 4967). Secondary antibodies: anti-rabbit IgG, HRP-linked (CST, 7074), anti-mouse IgG, HRP-linked (CST, 7076). Immunoblots were developed by ECL (West Pico or Femto, Thermo Scientific). 


\section{Restriction}

188 RNA was isolated from flash-frozen liver or brown adipose tissue by homogenization in TRIzol 189 Reagent (Thermo Fisher) followed by chloroform extraction and isopropanol precipitation. The 190 concentration of RNA was determined using a Nanodrop Spectrophotometer. RNA $(1 \mu \mathrm{g})$ was reverse transcribed using the Advanced cDNA Synthesis Kit (Bio-Rad). qPCR was performed using Power Up SYBR green (Bio-Rad) with duplicate technical replicates using the QuantStudio 5 Real-Time PCR system. $\Delta \Delta \mathrm{Ct}$ values were normalized to actin and relative expression was plotted. Primer sequences were: Asns forward: GCAGTGTCTGAGTGCGATGAA, Asns reverse: TCTTATCGGCTGCATTCCAAAC, Fgf21 forward: CTGCTGGGGGTCTACCAAG, Fgf21 reverse: CTGCGCCTACCACTGTTCC, Ucp1 forward: AGGCTTCCAGTACCATTAGGT, Ucp1 reverse: CTGAGTGAGGCAAAGCTGATTT.

\subsection{RNA-Seq}

Livers were collected from euthanized mice and immediately flash frozen in liquid nitrogen and stored at $-80^{\circ} \mathrm{C}$ until analysis. Livers were homogenized using a handheld homogenizer and RNA was extracted using a Qiagen RNeasy Plus Mini Kit (Qiagen \#74134). The concentration and purity of RNA was determined using a Nanodrop Spectrophotometer and confirmed using an Agilent 2100 Bioanalyzer. Libraries were prepared using the Illumina TruSeq Stranded Total RNA Sample reads (150bp length) per sample.

Reads were aligned to the mouse GRCm38.p6 assembly using the align function and annotated using the featureCounts function from the Rsubread package (version 2.3.7). Differential expression analysis was performed using the edgeR (3.30.3) and limma (3.44.3) packages. Gene symbols were mapped to Entrez IDs using the mapIds function from the AnnotationDbi package (1.51.1). Cluster analysis was performed using the degPatterns function from the DEGreport (1.24.1) package. Normalization was performed using the trimmed mean of $\mathrm{M}$-values method as implemented in the calcNormFactors from edgeR. Data were modeled and differential expression was determined using the limma voom pipeline to generate linear models with empirical Bayes moderation. Differential expression was determined using a Benjamini-Hochberg adjusted $\mathrm{p}$ value less than 0.05 . Once differentially expressed genes or gene clusters were determined, gene set enrichment analysis was determined using the enrichKEGG function from the clusterProfiler package (3.16.0) (52). Weighted gene correlation network analysis was performed using the WGCNA package (1.70-3) (53). Transcription factor (TF) binding analyses were performed using CiiiDER (54).

\subsection{Statistics}

220

Statistical analyses were performed in Prism (version 8, GraphPad Software) and mean values were plotted with error bars representing standard deviations. One-way ANOVAs were followed by either Tukey's post-hoc test or Dunnett's post-hoc test. Transcriptomic data were analyzed using R (version 4.0.2) and multiple comparisons in transcriptomic data were corrected using the Benjamini-Hochberg false detection rate correction. 
bioRxiv preprint doi: https://doi.org/10.1101/2021.12.19.473355; this version posted December 21, 2021. The copyright holder for this preprint (which was not certified by peer review) is the author/funder, who has granted bioRxiv a license to display the preprint in perpetuity. It is made

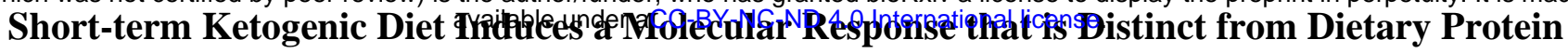

\section{Restriction}

\section{Results}

\subsection{Short-term dietary protein or carbohydrate restriction reduces body weight and adiposity in} mice

In order to evaluate the contribution of protein restriction to the metabolic and molecular adaptations elicited by KD, mice were fed six distinct diets: Low-fat control containing $20 \%$ of energy from protein (CTL) or $0 \%$ of energy from protein (PF), classical KD containing no carbohydrate and $10 \%$ energy from protein $(\mathrm{KD} 10 \mathrm{P})$, modified $\mathrm{KD}$ for which half or all protein content was replaced with carbohydrate (KD5P or KD0P), or KD with protein content normalized to the control diet (KD20P) (Fig. 1A; Fig. S1, A-B).

16-week-old male B6D2F1 mice were fed the above diets for 8 days. Body weight and food consumption were tracked across the diet period (Fig. S1, C-D). All experimental diets resulted in significant weight loss compared to mice fed the CTL diet, with KDOP resulting in the greatest magnitude of weight loss (18.8\% reduction) (Fig. 1B). A similar degree of weight loss was observed following PF and KD10P diets (11.7\% and 10.2\% reduction, respectively). All diets tended to have a lower calorie intake versus control, but only KDOP had a statistically significant decrease (Fig. 1C). Weight loss was primarily attributed to significant reductions in fat mass, which was observed in all diet groups, except KD20P (Fig. 1D). However, significant reductions in lean mass were also observed in $\mathrm{PF}$ and KD0P groups (Fig. 1E). Liver weight was also reduced following all experimental diets, with KD0P and KD5P groups significantly different from CTL mice (Fig. 1F).
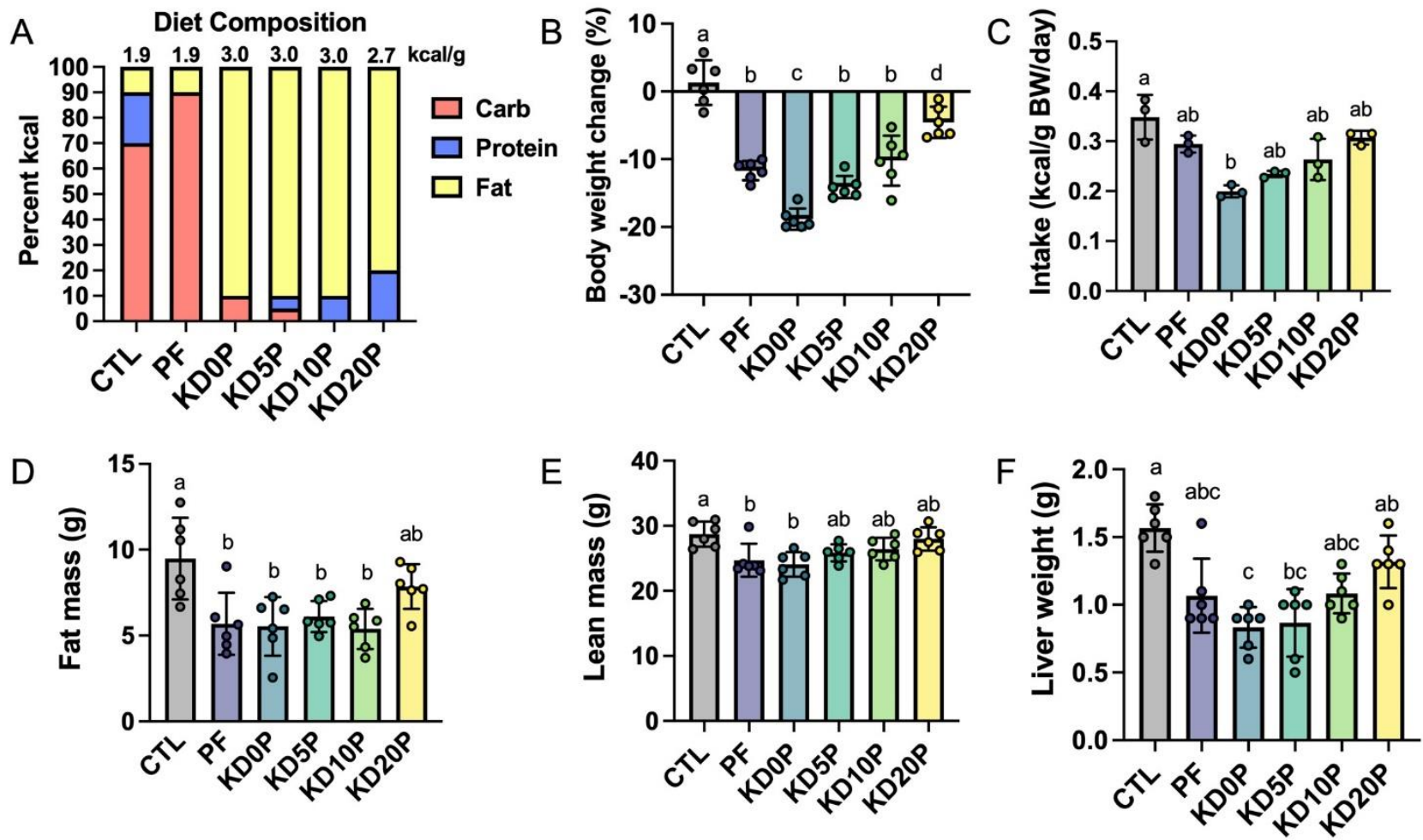

Figure 1. Short-term dietary protein or carbohydrate restriction alters body composition. Male B6D2F1 mice were fed one of six diets for 8 days ( $n=6$ per diet) with varying macronutrient compositions as depicted in (A). The energy density of each diet is listed above the associated bar. (B) Changes in body weight after 8 days of diet shown as the percent of the initial weight. (C) Average energy intake across 8 days of diet feeding. Intake was normalized to the summed body weight 
bioRxiv preprint doi: https://doi.org/10.1101/2021.12.19.473355; this version posted December 21,2021 . The copyright holder for this preprint

(which was not certified by peer review) is the author/funder, who has granted bioRxiv a license to display the preprint in perpetuity. It is made

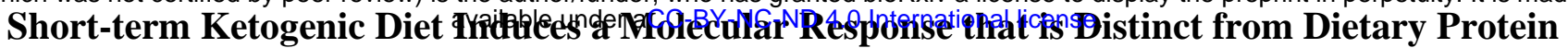
Restriction

of 2 mice co-housed per cage and presented per cage. Fat mass (D) and lean mass (E) quantified by EchoMRI at the end of the diet period. (F) Liver weights at sacrifice after 6 hours fasting period. Statistical analysis was performed by one-way ANOVA with Tukey's multiple comparison test (A-D) or Kruskal-Wallis with Dunn's test (E-F). Different letters indicate significant differences $(\mathrm{p}<0.05)$ between groups, with common letters indicating no significant difference. Values are represented as mean $\pm \mathrm{SD}$.

\subsection{Protein-free, but not ketogenic, diet improves insulin sensitivity following short-term feeding}

256 To evaluate the metabolic effects of short-term protein or carbohydrate restriction, markers of systemic glucose homeostasis were assessed. Mice fed PF and KD diets, except for KD20P, had reduced fasting blood glucose and serum insulin after one week (Fig. 2, A-B). KD diets resulted in elevated fasting ketone levels, which was blunted by the addition of protein beyond 10\% kilocalories (KD20P) (Fig. 2C). Increased ketone levels were not observed in mice fed PF.

261 Glucose and insulin tolerance were further assessed in a separate cohort of mice fed CTL, PF, or KD10P diets ( $\mathrm{n}=4$ per diet). Neither PF nor KD10P diets significantly affected glucose tolerance (Fig. 2D-E; Fig. S2A-B). Despite the lack of significant change in glucose tolerance, serum insulin concentrations during the GTT were significantly lower in both PF-and KD- fed mice (Fig. 2F-G), suggesting that PF and KD10P may increase insulin sensitivity. However, only PF-fed mice demonstrated improved insulin tolerance, while KD10P-fed mice tended to have worse insulin tolerance, compared to CTL-fed mice (Fig. 2H-I; Fig. S2C-D). To evaluate whether PF or KD10P diets enhanced the hepatic response to insulin, insulin/Akt signalling was assessed in liver tissue following intraperitoneal insulin injection. Phosphorylation of Akt and its target, FoxO1, tended to increase in response to insulin in livers from PF compared to CTL mice (Fig. 2J; Fig. S2E-F). Insulin/Akt signalling tended not to be enhanced in livers from KD10P compared to CTL mice. 


\section{Restriction}
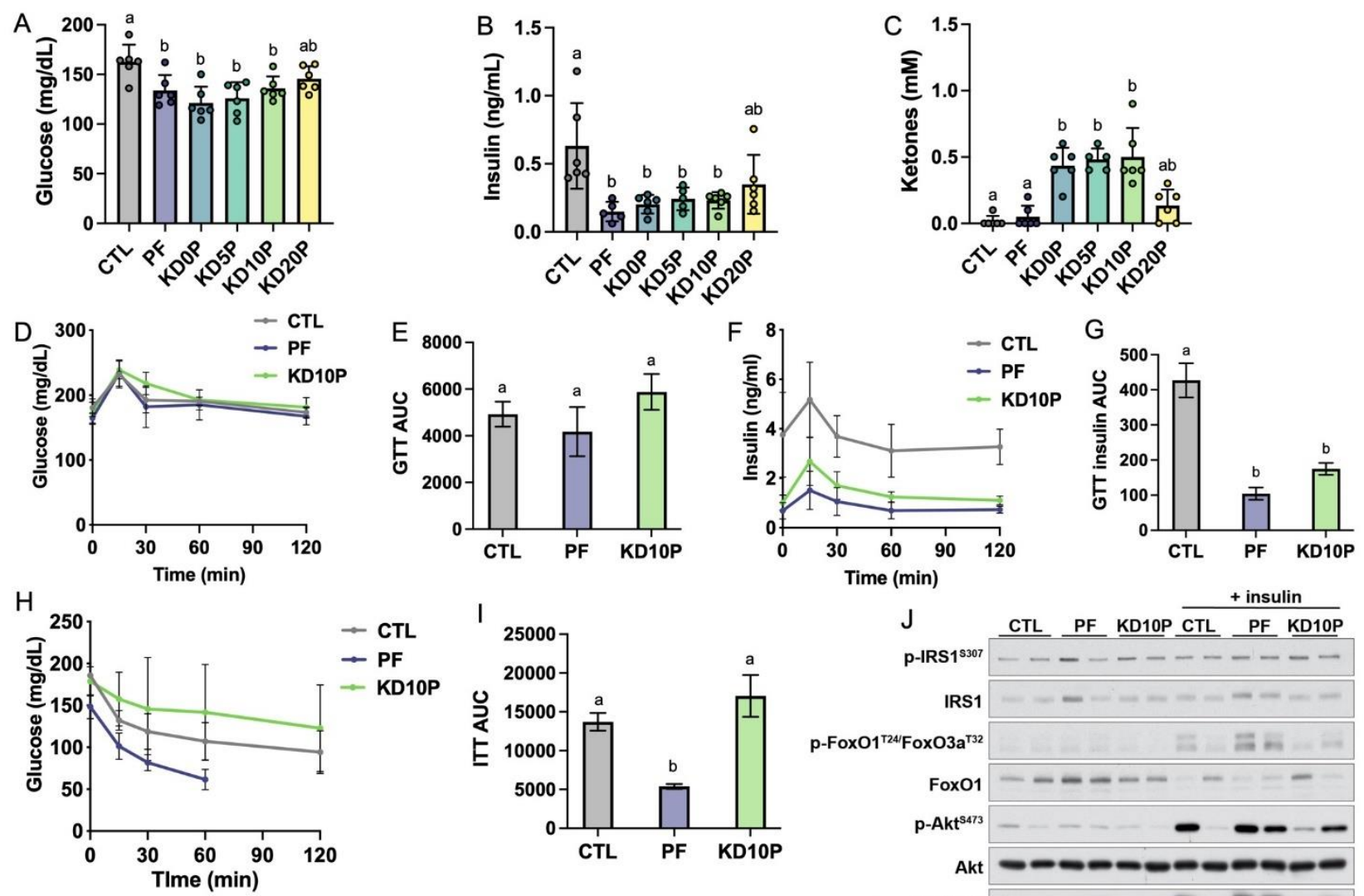

Figure 2. Protein-free, but not ketogenic, diet improves insulin sensitivity following short-term feeding. After 8 days of diet feeding, mice were fasted for 6 hours prior to sacrifice $(n=6$ per diet). Blood was collected and blood glucose (A) and ketones (B) were measured with handheld meters. (C) Serum insulin was measured by ELISA. (D) Blood glucose levels during an oral glucose tolerance test (OGTT) in a separate cohort of 6-hour fasted mice fed experimental diets for 5 days ( $\mathrm{n}=4$ per diet) and (E) corresponding area under the curve (AUC). (F) Serum insulin measurements collected during the OGTT and (G) corresponding AUC. (H) Blood glucose levels during an insulin tolerance test in 4-hour fasted mice fed experimental diets for 7 days ( $\mathrm{n}=4$ per diet) and (I) corresponding AUC. Measurements were halted after 60 minutes in PFfed mice due to severe hypoglycemia. (J) Mice fed experimental diets for 10 days were fasted for 6 hours and then injected intraperitoneally with vehicle or insulin and sacrificed after 20 minutes. Immunoblots show insulin/Akt/mTORC1 signaling in liver lysates ( $\mathrm{n}=2$ per diet per treatment). Statistical analysis was performed by one-way ANOVA with Tukey's multiple comparison test (A, E, F, I) or Kruskal-Wallis with Dunn's test (B-C). Different letters indicate significant differences ( $<$ 0.05 ) between groups, with common letters indicating no significant difference. Values are represented as mean \pm SD.

\subsection{Protein-free, but not ketogenic, diets induce molecular markers of dietary protein restriction}

Next, we aimed to determine whether ketogenic diets induce established markers of protein restriction, including serum FGF21 levels, hepatic Fgf21 and Asns mRNA expression and brown adipose tissue (BAT) Ucp1 mRNA expression. Serum FGF21 was increased $\sim 5$-fold in mice fed either protein-free diets, PF or KD0P, compared to CTL mice (Fig. 3A). Serum FGF21 was also significantly increased in mice fed KD5P, but to a lesser extent, and was not increased in mice fed either KD10P or KD20P, compared to CTL mice. 


\section{Restriction}

292

293

294

295

The adaptation to dietary protein restriction includes upregulation of activating transcription factor 4 (ATF4) gene targets Fgf21 and Asns in the liver, as well as upregulation of Ucp1 expression in BAT. Next, we compared the induction of these gene signatures by PF and KD diets. As expected, liver Fgf 21 and Asns expression was elevated in mice fed PF (Fig. 3B-C). However, neither Fgf21 nor Asns
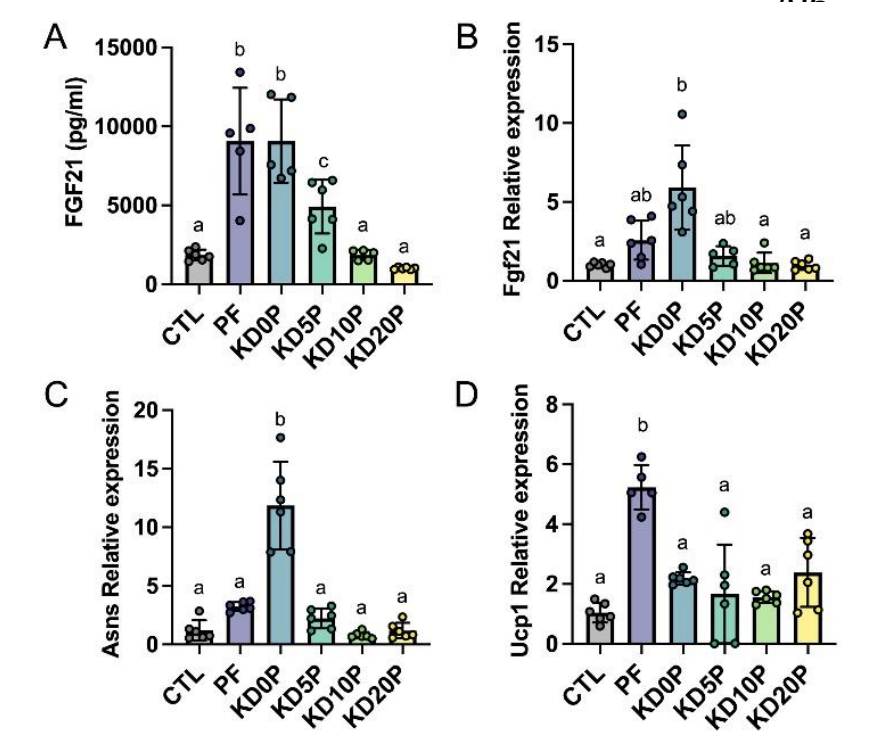

expression was increased in the liver of mice fed KDs containing at least $5 \%$ protein (Fig. 3B-C). In agreement with previous reports, BAT Ucpl expression was significantly elevated in mice fed PF compared to those fed CTL ( $\sim 5$-fold, Fig. 3D). While BAT Ucpl expression was slightly increased in mice fed either of the KD diets compared to those fed the CTL diet, none of these differences were significant. Interestingly, although mice fed the protein-free KD, KD0P, demonstrated significantly greater elevations in hepatic Fgf2l ( 2-fold difference) and Asns expression ( 4-fold difference) compared to mice fed the carbohydrate-rich PF diet, they showed only equivalent or less circulating FGF21 and BAT Ucpl expression (Fig. 3A-D).
312

313

314

315

316

317

318

319

320

321

322

323

324

325

326

327

328

329

330

331

332

333

334

335

336

337
Figure 3. Protein-free, but not ketogenic, diets induce molecular markers of dietary protein restriction. (A) Serum FGF21 was measured in 6-hour fasted mice fed experimental diets for 8 days. Liver gene expression of Fgf2l (B) and Asns (C) and brown adipose tissue expression of Ucpl (D) were measured by RT-qPCR and normalized to actin expression. Statistical analysis was performed by one-way ANOVA with Tukey's multiple comparison test (A, C-D) or Kruskal-Wallis with Dunn's test (B). Different letters indicate significant differences $(\mathrm{p}<0.05)$ between groups, with common letters indicating no significant difference. Values are represented as mean $\pm \mathrm{SD}$.

\subsection{Protein-free and ketogenic diets produce distinct hepatic transcriptomic signatures}

To further explore changes in hepatic gene expression as a function diet, we performed RNA sequencing. Data reduction by multidimensional scaling showed distinct clustering of samples by group with KD20P showing the least divergence from CTL and KD0P showing the greatest divergence (Fig. 4A). Key genes in the amino acid restriction response showed a greater relative increase in KD0P vs PF, and no response in KD10P, including Fgf21, Asns and Psat1 (Fig. 4B-D). Interestingly, although Atf4 expression was similarly elevated in KD0P compared to PF livers, it also tended to increase across the other KD groups (FigS3A), suggesting it may not be a key driver of this response. When weighted gene correlation network analysis (WGCNA) was performed, a single module containing these three genes (Fgf21, Psat1, Asns) was identified. This module contained 51 genes which exhibited similar behavior across groups including a proportionally greater increase in KD0P vs PF (Fig. S3B). Several other genes characteristic of the amino acid stress response were identified in this module including tRNA synthetases (Yars, Cars, Mars, Farsa, Rars), Pck2 and Mthfd2. When transcription factor (TF) binding site analysis was performed, binding motifs for Ventx, Thap11, Atf4 and Sox21 were the top enriched hits compared to a background list of 1000 random genes (Fig. S4C). Binding motifs for multiple FOX family TFs were significantly depleted in this module, including Foxo4, Foxo6 and Foxl1 (Fig. S3C).

To better understand how gene networks change in response to the experimental diets, unsupervised clustering of the most variable $10 \%$ of genes in the dataset was performed. Six major clusters were 
bioRxiv preprint doi: https://doi.org/10.1101/2021.12.19.473355; this version posted December 21, 2021. The copyright holder for this preprint

(which was not certified by peer review) is the author/funder, who has granted bioRxiv a license to display the preprint in perpetuity. It is made

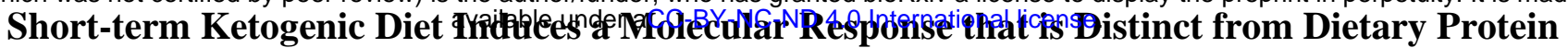
Restriction

338 identified from this analysis (Fig. 4E). Clusters 1 and 2 responded to dietary protein content by linearly 339 decreasing or increasing respectively. Clusters 3 and 4 were either increased or decreased respectively 340 by the classic ketogenic diet (KD10P). Clusters 5 and 6 were comprised of genes which increased or 341 decreased respectively as a function of increased dietary fat content, largely independent of ketosis.

342 Gene set overrepresentation analysis showed that the genes linearly responding to protein content were 343 largely involved in amino acid metabolic processes, fatty acid metabolism and CoA metabolic 344 processes (Fig. 4F). Cluster 3 (increasing with classic KD) was enriched for genes involved in 345 oxidative phosphorylation, lipid catabolism and nucleotide metabolic processes, which were not observed in the protein responsive clusters. There was some overlap between clusters 1 and 3 regarding amino acid catabolic processes. The pathways increased in response to increased dietary fat content (cluster 5) were primarily involved in lipid metabolism and CYP regulation. Interestingly, pathways enriched in genes that decreased in response to dietary fat tended to overlap with those that were increased in response to classic $\mathrm{KD}$, particularly those involving nucleotide metabolism.

To investigate TFs that may be regulating these differential responses to diet, binding site motif analysis was performed across the clusters. To determine TFs that may be enriched in response to low protein, the overlap of TFs significantly depleted in cluster 1 and significantly enriched in cluster 2 was taken. A similar approach was taken to identify TFs enriched by KD using clusters 3 and 4 , and TFs enriched by high fat using clusters 5 and 6 . In the low protein condition, motifs for Atf 1 , Ahr::Arnt and E2F6 binding were among the most enriched (Fig. 4G, Fig. S3D-E). In the KD condition, binding sites for FOS and JUN family proteins were highly enriched including Fos, Fosb, Fosl1 and Fosl2 (Fig. 4G, Fig. S3F-G). In the high fat condition, binding motifs for HOX and SOX family proteins were significantly enriched, independent of ketogenesis (Fig. 4G, Fig. S4H-I). 
bioRxiv preprint doi: https://doi.org/10.1101/2021.12.19.473355; this version posted December 21, 2021. The copyright holder for this preprint (which was not certified by peer review) is the author/funder, who has granted bioRxiv a license to display the preprint in perpetuity. It is made

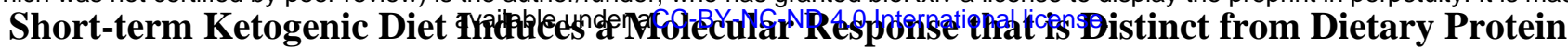
Restriction

A
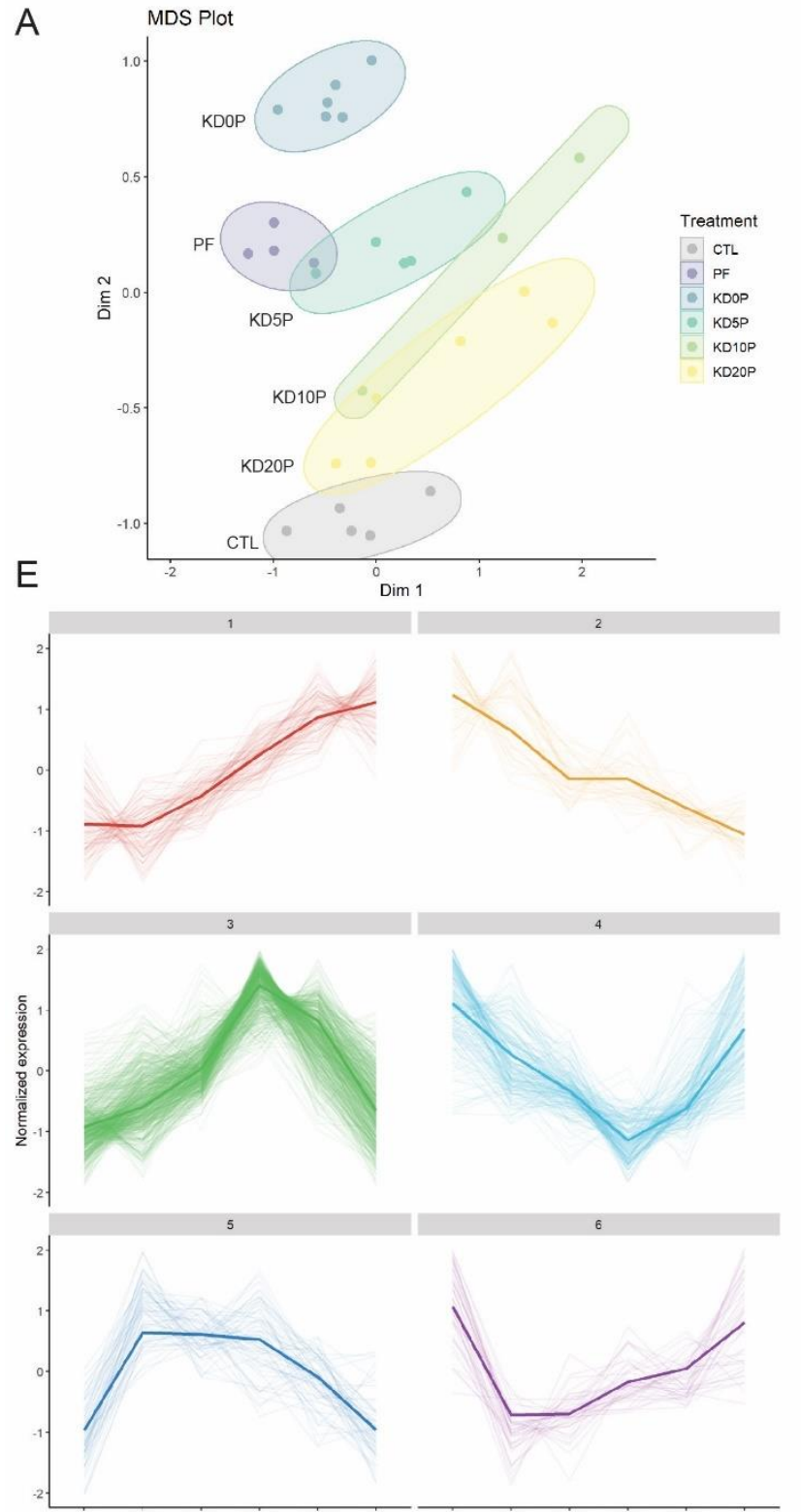
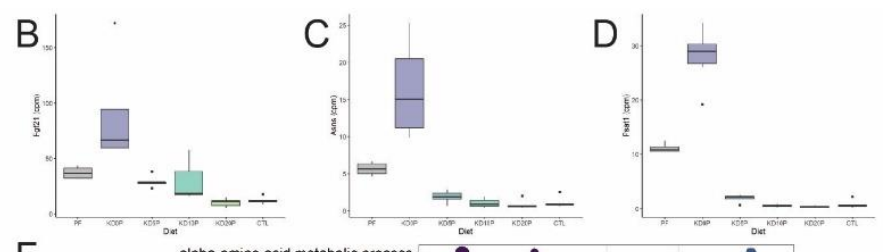

$\mathrm{F}$

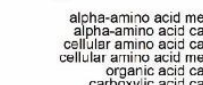

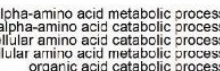

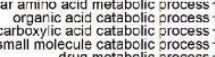

small molecule catabolic rocess
drug metabolic process

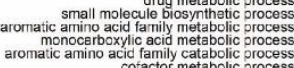

carboxylic aciactor metabolic process

organic acc

alpha-arniino acid biossynthnthic process
arginine metabotic process-

cellular amino aninine metabolic prosynthecesic process
coenzymme metabolic proces

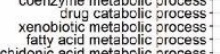

xenobiotic metabolic process
fattly acid metaboblic rocess
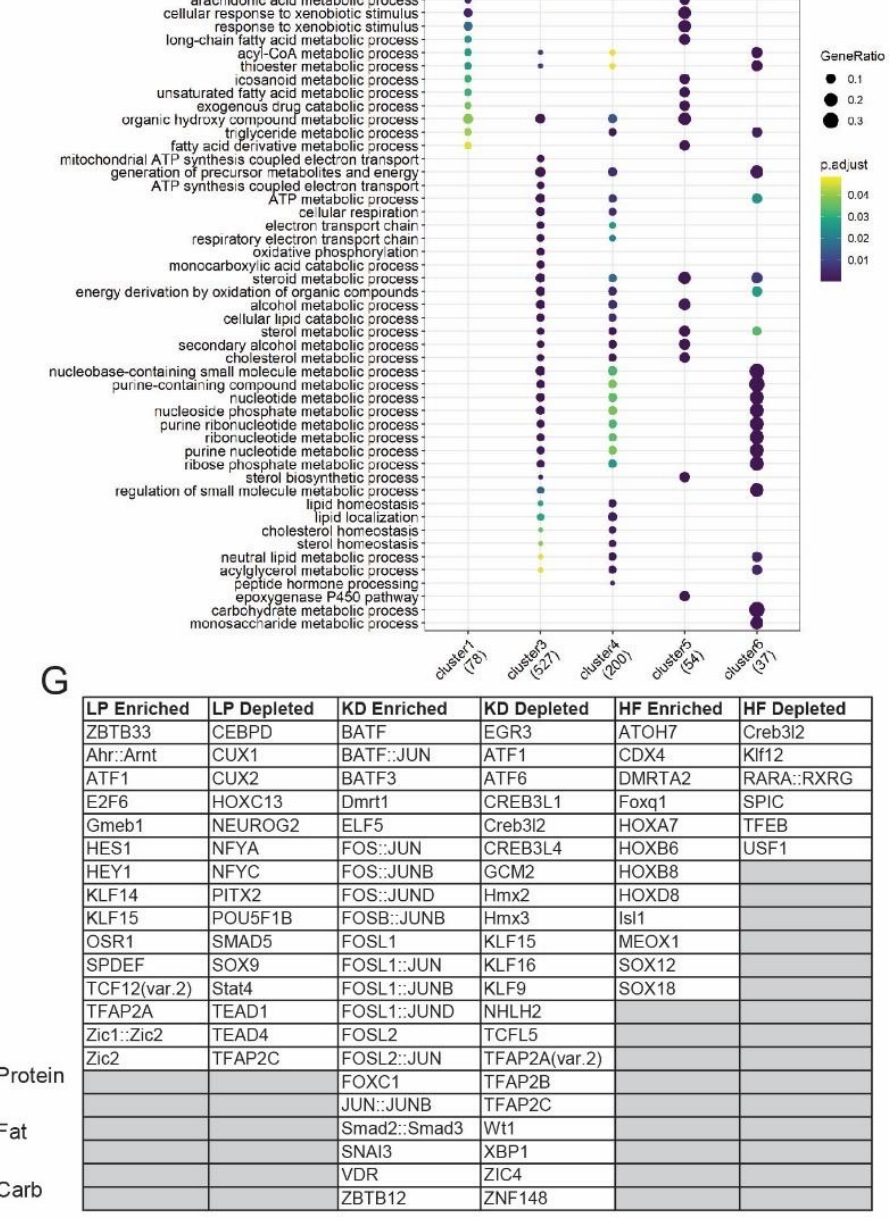

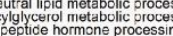

\begin{tabular}{l} 
peptice hormone processing. \\
epoxygenase \\
\hline 450 pathway
\end{tabular}

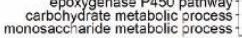

G

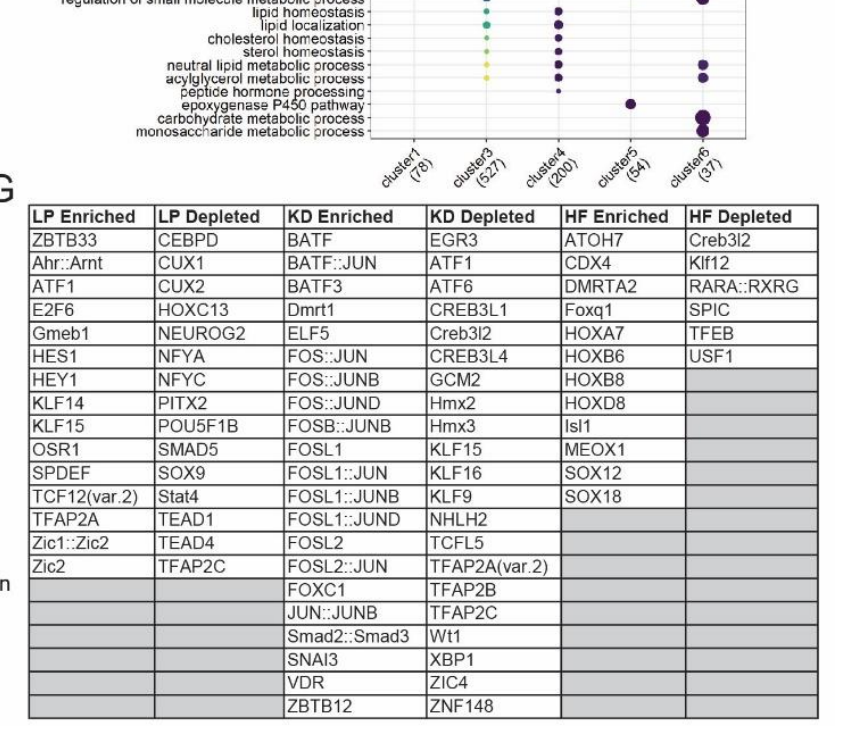

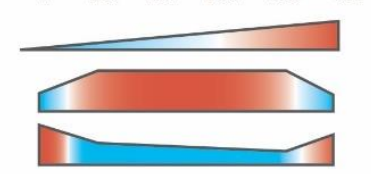

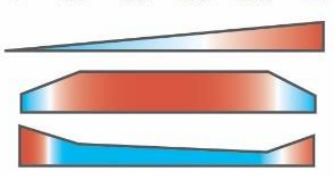

Figure 4. Protein-free and ketogenic diets produce distinct hepatic transcriptomic signatures. (A) genes Fgf21, (C) Asns and (D) Psat1 presented at counts per million (cpm). (E) Cluster analysis of the top 10\% of most variable genes in the dataset. Clusters 1 and 2 represent protein-responsive genes. Clusters 3 and 4 represent genes responding to classic ketogenic diet. Clusters 5 and 6 include genes responsive to dietary fat content. (F) Pathway over-representation analysis of genes from the clusters identified in E. (G) Enriched and depleted transcription factor (TF) binding motifs in the clusters identified in E. LP enriched includes TF binding motifs which are significantly depleted in cluster 1 and significantly enriched in cluster 2 . The same method was used for KD in clusters 3 and 4 and high fat (HF) in clusters 5 and 6. 


\section{Restriction}

\section{Discussion}

372 This study utilized six distinct diets to dissect the influence of protein content on the short-term 373 metabolic adaptations to the high-fat, low-carbohydrate ketogenic diet. Mice fed a protein-free diet (PF) or one of three ketogenic diets with $10 \%$ or less protein lost weight, which was primarily attributed to loss of fat mass, and had reduced fasting blood glucose and insulin levels. Despite similar physiological effects of $\mathrm{KD}$ and $\mathrm{PF}$ diets, the diets differed with respect to some metabolic and molecular markers. While mice fed PF demonstrated improved insulin sensitivity and liver insulin signaling, mice fed KD did not. With the exception of the protein-free KD (KDOP), KD diets did not lead to elevations in serum or tissue markers of protein restriction, including circulating FGF21, hepatic Fgf2l and Asns and BAT Ucpl expression. Furthermore, PF and classic KD diets elicited distinct changes in global gene expression. These data indicate that KD does not induce a molecular response to protein restriction and that $\mathrm{PF}$ and $\mathrm{KD}$ diets impact health and metabolism via different underlying mechanisms.

Defining the effects of KD on metabolic health has been complicated by discrepancies in diet composition across studies, particularly in studies which use "control chow" diets. KD diets in published rodent studies contain between $4.5-10 \%$ protein with feeding durations from 3 days to 14 months. The present study helps clarify discrepancies by using standardized semi-purified diets that control for micronutrient composition and span the range of protein content found in published KD diets. In addition to $\mathrm{KD}$ diet composition, published studies differ with respect to control diet formulation. For studies that utilize a semi-purified ketogenic diet, the control diet should also be semipurified in order to ensure that differences in micronutrient content or nutrient source do not account for any of the phenotypic observations attributed to macronutrients. The diets used in the present study were prepared from the same semi-purified ingredients in order to evaluate the precise contribution of individual macronutrients.

It is also important to note that some effects of KD may be specific to the duration of feeding. Our finding that mice fed $\mathrm{KD}$ for 8 days are insulin resistant is aligned with other studies of short-term KD $(12,13,55)$. However, studies in which mice were fed KD for 1 month (11) or 60 weeks (6) found improved insulin sensitivity, indicating additional adaptations to longer-term feeding. This study aimed to assess the physiological and molecular response to short-term feeding, which will be important for defining the potential therapeutic benefits of KD for recent cancer and weight loss indications.

The present study found no elevations in serum FGF21 and no induction of hepatic Fgf 21 expression in mice fed the classic KD containing $10 \%$ protein. While some published studies report increased plasma or hepatic FGF21 after 4-5 weeks (12,55), the KD used in these studies contained approximately $5 \%$ protein. Thus, our finding that FGF21 was only induced in response to KD containing $5 \%$ or less protein is consistent with these reports and demonstrates that the effects of ketogenesis can be disconnected from those of FGF21. Furthermore, by carefully titrating the levels of protein in $\mathrm{KD}$, we demonstrate that circulating FGF21 is induced in response to decreasing dietary protein content, further establishing it as a marker of protein restriction. This result is consistent with a published report demonstrating that low protein, high carbohydrate diets are associated with maximal FGF21 induction (56) and demonstrates that KD may act independently of dietary protein restriction to elicit metabolic or other health benefits. Therefore, we propose that future studies on KD utilize diets containing at least $10 \%$ protein in order to ensure that observations are due to carbohydrate

413 restriction, rather than protein restriction. 

Restriction

414 FGF21 signaling in the central nervous system (CNS) has contributes to increased food intake during 415 low-protein diet (5\% protein) feeding, a phenomenon known as protein leverage (57). However, FGF21 416 signaling is not sufficient to overcome reduced food intake and body weight in response to very-lowprotein diets (1\% protein). This decrease in intake is at least partially attributed to reduced hypothalamic mTOR signaling $(58,59)$. Interestingly, increased BAT Ucpl expression requires intact FGF21 signaling in the brain, but not in the adipose tissue (57). In our study, mice fed the high-fat, protein-free diet (KD0P) had equal serum FGF21 and hepatic Fgf21 expression levels vs highcarbohydrate PF-fed mice. However, the KD0P group had significantly reduced energy intake and did not have elevated BAT Ucpl expression compared to mice fed CTL and PF diets. Given that brain FGF21 signaling promotes energy intake and is required for Ucpl induction, it is possible that these characteristics of mice fed the high-fat KD0P are a result of FGF21 resistance, which has been associated with high-fat diet-induced obesity in mice (60). This may also explain why markers of protein restriction are induced in response to KDOP in the liver, but not BAT.

Consistent with this observed difference, on the transcriptional level PF and KD drove divergent gene expression programs. First, the overall transcriptional response to PF diet was amplified by substituting carbohydrate for fat (PF vs KD0P, Fig. 4A). The high fat background drove higher expression of multiple genes involved in amino acid synthesis including Psat1, Phgdh and Asns, as well as the amino acid responsive transcription factor Atf4. WGCNA analysis identified a module containing these amino acid responsive genes which were further increased by high fat background. Atf4 was the third-most enriched TF-binding motif among these genes. However, Atf4 transcript level also increased in KDs where these amino acid-related targets did not increase. This leaves an open question about the role of ATF4 in driving this differential expression in response to KDOP vs PF.

Clustering analysis reveal expression modules which were responsive to protein, to classic $\mathrm{KD}$ (KD10P) and to fat content independent of protein or ketogenesis. Interestingly, the largest number of genes were positive responders to classic KD, with over 500 genes clustering in this pattern. The protein responsive clusters were primarily enriched for genes involved in amino acid metabolism and fatty acid metabolism, with increased expression of genes involved in non-essential amino acid synthesis and lipid degradation pathways. Among the most enriched pathways in the classic KD responsive gene set was oxidative phosphorylation, with expression of many mitochondrial genes, such as $N d u f a 10, S d h b$ and $S d h c$ increased in response to KD10P. Interestingly, these genes tended to be suppressed by reduced protein, even in the high fat background. Similarly, nucleotide metabolic processes were also enriched in response to classic KD (cluster 3). These pathways show some overlap with mitochondrial-related pathways and include genes like Mpc2, Upp2 and Pmvk. Many of these nucleotide-related processes tended to show an overall suppression by high fat diet, suggesting that these increases are specific to the classic ketogenic diet, and not just due to high fat content. TF analyses showed enrichment of Atf and Hif signaling in low protein groups, with Atf1, Atf7 and Hif/Arnt showing strong enrichments. In the KD clusters, binding motifs for Fos/Jun were robustly enriched. These differential TF signatures support the divergent expression profiles seen in the gene expression analysis.

While this study clarifies that protein restriction shows relatively little overlap with $\mathrm{KD}$, multiple outstanding questions remain. In particular, it will be important to understand how the molecular and metabolic adaptations to KD differ across feeding duration and how short versus long-term adaptations are connected to stress resistance, weight loss and glucose homeostasis. In addition, it is unknown how ketosis or other KD-induced alterations impart the associated physiological changes. The transcriptomics data presented here provide novel insight into potential underlying mechanisms of KD and can serve as a starting point for future mechanistic studies. In conclusion, KD and protein-restricted 


\section{Restriction}

460 diets produce similar physiological outcomes, though through distinct mechanisms, and more work is 461 needed to define how short-term KD may be utilized therapeutically.

4635 Conflict of Interest

464 The authors declare that the research was conducted in the absence of any commercial or financial 465 relationships that could be construed as a potential conflict of interest.

4676 Author Contributions

468 J.M., M.M., S.M., and K.K. conceived of and designed the study. K.K., M.M., and S.M. performed 469 experiments. K.K. and M.M. analyzed and interpreted the data. M.M. performed transcriptomic 470 analyses. K.K. and M.M. drafted the manuscript, which was reviewed by S.M.

\section{$472 \quad 7 \quad$ Funding}

473 This work was supported by grants from the NIH/NIA (1F31AG064863-01) to M.M.

\section{Acknowledgments}

We thank members of the Mitchell Lab for critical discussions on study design and data. We also thank Brendan Manning for support and input during manuscript drafting.

478

\section{Data Availability Statement}

480 The RNA seq datasets generated for this study can be found on the NIH Sequence Read Archive 481 (SRA) under the BioProject PRJNA777819: Profiling the hepatic transcriptional response to low protein versus low carbohydrate diets. A companion web-based application for data exploration is published at macarthur.shinyapps.io/kdshiny .

\section{References}

486 1. McCay CM, Crowell MF, Maynard LA. The effect of retarded growth upon the length of life 487 span and upon the ultimate body size. 1935. Nutrition (1989) 5(3):155-71; discussion 72. Epub 488 1989/05/01. PubMed PMID: 2520283.

489 2. Fontana L, Partridge L. Promoting health and longevity through diet: from model organisms 490 to humans. Cell (2015) 161(1):106-18. Epub 2015/03/31. doi: 10.1016/j.cell.2015.02.020. PubMed 491 PMID: 25815989; PubMed Central PMCID: PMCPMC4547605. 


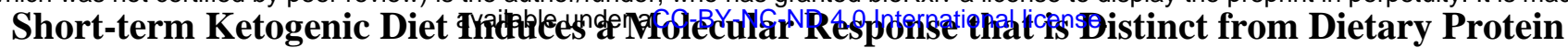
Restriction

492 3. Osborne TB, Mendel LB, Ferry EL. THE EFFECT OF RETARDATION OF GROWTH 493 UPON THE BREEDING PERIOD AND DURATION OF LIFE OF RATS. Science (New York, NY) (1917) 45(1160):294-5. Epub 1917/03/23. doi: 10.1126/science.45.1160.294. PubMed PMID: 17760202.

4. Trocha KM, Kip P, Tao M, MacArthur MR, Treviño-Villarreal JH, Longchamp A, et al.

Short-term preoperative protein restriction attenuates vein graft disease via induction of cystathionine $\gamma$-lyase. Cardiovascular research (2020) 116(2):416-28. Epub 2019/03/30. doi: 10.1093/cvr/cvz086. PubMed PMID: 30924866; PubMed Central PMCID: PMCPMC8204489.

500 5. Greco T, Glenn TC, Hovda DA, Prins ML. Ketogenic diet decreases oxidative stress and improves mitochondrial respiratory complex activity. Journal of cerebral blood flow and metabolism : official journal of the International Society of Cerebral Blood Flow and Metabolism (2016) 36(9):1603-13. Epub 2015/12/15. doi: 10.1177/0271678x15610584. PubMed PMID: 26661201; PubMed Central PMCID: PMCPMC5012517.

506 2017/09/07. doi: 10.1016/j.cmet.2017.08.005. PubMed PMID: 28877457; PubMed Central PMCID: PMCPMC5609489.

7. Green CL, Lamming DW. Regulation of metabolic health by essential dietary amino acids. Mechanisms of ageing and development (2019) 177:186-200. Epub 2018/07/26. doi: 10.1016/j.mad.2018.07.004. PubMed PMID: 30044947; PubMed Central PMCID:

512 PMCPMC6333505.

513 8. Solon-Biet SM, Mitchell SJ, Coogan SC, Cogger VC, Gokarn R, McMahon AC, et al. Dietary 514 Protein to Carbohydrate Ratio and Caloric Restriction: Comparing Metabolic Outcomes in Mice. Cell Rep (2015) 11(10):1529-34. Epub 2015/06/02. doi: 10.1016/j.celrep.2015.05.007. PubMed PMID: 26027933; PubMed Central PMCID: PMCPMC4472496.

517 9. MacArthur MR, Mitchell SJ, Treviño-Villarreal JH, Grondin Y, Reynolds JS, Kip P, et al. 518 Total protein, not amino acid composition, differs in plant-based versus omnivorous dietary patterns and determines metabolic health effects in mice. Cell Metabolism (2021) 33(9):1808-19.e2. doi: https://doi.org/10.1016/j.cmet.2021.06.011.

10. Maida A, Zota A, Vegiopoulos A, Appak-Baskoy S, Augustin HG, Heikenwalder M, et al. Dietary protein dilution limits dyslipidemia in obesity through FGF21-driven fatty acid clearance. The Journal of nutritional biochemistry (2018) 57:189-96. Epub 2018/05/12. doi: 10.1016/j.jnutbio.2018.03.027. PubMed PMID: 29751292. amino acid metabolism permit normal longevity in mice consuming a low-carbohydrate ketogenic diet. Biochim Biophys Acta (2015) 1852(10 Pt A):2056-65. Epub 2015/07/15. doi: 10.1016/j.bbadis.2015.07.009. PubMed PMID: 26170063; PubMed Central PMCID: PMCPMC4862866. 
bioRxiv preprint doi: https://doi.org/10.1101/2021.12.19.473355; this version posted December 21, 2021. The copyright holder for this preprint

(which was not certified by peer review) is the author/funder, who has granted bioRxiv a license to display the preprint in perpetuity. It is made

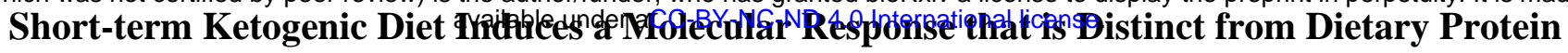
Restriction

535 13. Grandl G, Straub L, Rudigier C, Arnold M, Wueest S, Konrad D, et al. Short-term feeding of 536 a ketogenic diet induces more severe hepatic insulin resistance than an obesogenic high-fat diet. $J$ Physiol (2018) 596(19):4597-609. Epub 2018/08/09. doi: 10.1113/JP275173. PubMed PMID: 30089335; PubMed Central PMCID: PMCPMC6166091.

539 14. Kennedy AR, Pissios P, Otu H, Roberson R, Xue B, Asakura K, et al. A high-fat, ketogenic diet induces a unique metabolic state in mice. Am J Physiol Endocrinol Metab (2007) 292(6):E172439. Epub 2007/02/15. doi: 10.1152/ajpendo.00717.2006. PubMed PMID: 17299079.

543

15. Treviño-Villarreal JH, Reynolds JS, Bartelt A, Langston PK, MacArthur MR, Arduini A, et al. Dietary protein restriction reduces circulating VLDL triglyceride levels via CREBH-APOA5dependent and -independent mechanisms. JCI insight (2018) 3(21). Epub 2018/11/06. doi: 10.1172/jci.insight.99470. PubMed PMID: 30385734; PubMed Central PMCID: PMCPMC6238732.

16. Peterman MG. The Ketogenic Diet in Epilepsy. JAMA (1925) 84(26):1979-83.

17. Talbot FB, Metcalf KM, Moriarty ME. A Clinical Study of Epileptic Children Treated by Ketogenic Diet. Boston Medical and Surgical Journal (1927) 196(3):89-96.

18. Helmholz HF. The Treatment of Epilepsy in Childhood. JAMA (1927) 88(26):2028-32.

19. Neal EG, Chaffe H, Schwartz RH, Lawson MS, Edwards N, Fitzsimmons G, et al. The ketogenic diet for the treatment of childhood epilepsy: a randomised controlled trial. Lancet Neurol (2008) 7(6):500-6. Epub 2008/05/06. doi: 10.1016/S1474-4422(08)70092-9. PubMed PMID: 18456557.

554 20. Barborka CJ. Ketogenic Diet Treatment of Epilepsy in Adults. JAMA (1928) 91(2):73-8. intractable epilepsy in adults: A meta-analysis of observational studies. Epilepsia Open (2018) 3(1):9-17. Epub 2018/03/29. doi: 10.1002/epi4.12098. PubMed PMID: 29588983; PubMed Central PMCID: PMCPMC5839310.

22. Malvy D, Maingourd C, Pengloan J, Bagros P, Nivet H. Effects of severe protein restriction with ketoanalogues in advanced renal failure. J Am Coll Nutr (1999) 18(5):481-6. Epub 1999/10/08. doi: 10.1080/07315724.1999.10718887. PubMed PMID: 10511331. effects of two low protein diets in chronic kidney disease stage 4-5--a randomized controlled trial. Nephrol Dial Transplant (2008) 23(2):636-44. Epub 2007/11/06. doi: 10.1093/ndt/gfm576. PubMed PMID: 17981885.

566 24. Maschio G, Oldrizzi L, Tessitore N, D'Angelo A, Valvo E, Lupo A, et al. Effects of dietary 567 protein and phosphorus restriction on the progression of early renal failure. Kidney international 568 (1982) 22(4):371-6. Epub 1982/10/01. doi: 10.1038/ki.1982.184. PubMed PMID: 7176336. restriction on the progression of renal insufficiency. N Engl J Med (1989) 321(26):1773-7. Epub 1989/12/28. doi: 10.1056/NEJM198912283212601. PubMed PMID: 2512486.

572 26. Riccio E, Di Nuzzi A, Pisani A. Nutritional treatment in chronic kidney disease: the concept 573 of nephroprotection. Clin Exp Nephrol (2015) 19(2):161-7. Epub 2014/10/17. doi: 10.1007/s10157574 014-1041-7. PubMed PMID: 25319188.

575 27. Bueno NB, de Melo IS, de Oliveira SL, da Rocha Ataide T. Very-low-carbohydrate ketogenic 576 diet v. low-fat diet for long-term weight loss: a meta-analysis of randomised controlled trials. $\mathrm{Br} J$ 


\section{Restriction}

Nutr (2013) 110(7):1178-87. Epub 2013/05/09. doi: 10.1017/S0007114513000548. PubMed PMID: 23651522.

28. Rigalleau V, Combe C, Blanchetier V, Aubertin J, Aparicio M, Gin H. Low protein diet in uremia: effects on glucose metabolism and energy production rate. Kidney international (1997) 51(4):1222-7. Epub 1997/04/01. doi: 10.1038/ki.1997.167. PubMed PMID: 9083290. restriction on glucose and insulin metabolism in normal and diabetic humans. Metabolism (1994) 43(4):462-7. Epub 1994/04/01. doi: 10.1016/0026-0495(94)90077-9. PubMed PMID: 8159104.

30. Linn T, Geyer R, Prassek S, Laube H. Effect of dietary protein intake on insulin secretion and glucose metabolism in insulin-dependent diabetes mellitus. The Journal of clinical endocrinology and metabolism (1996) 81(11):3938-43. Epub 1996/11/01. doi: 10.1210/jcem.81.11.8923841. PubMed PMID: 8923841. 2000/11/18. doi: 10.1007/s001250051521. PubMed PMID: 11079744. protein intake is associated with a major reduction in IGF-1, cancer, and overall mortality in the 65 and younger but not older population. Cell Metab (2014) 19(3):407-17. Epub 2014/03/13. doi: 10.1016/j.cmet.2014.02.006. PubMed PMID: 24606898; PubMed Central PMCID: PMCPMC3988204. enhances the efficacy of PI3K inhibitors. Nature (2018) 560(7719):499-503. Epub 2018/07/28. doi: 10.1038/s41586-018-0343-4. PubMed PMID: 30051890; PubMed Central PMCID: PMCPMC6197057.

34. Lien EC, Westermark AM, Zhang Y, Yuan C, Li Z, Lau AN, et al. Low glycaemic diets alter 602 lipid metabolism to influence tumour growth. Nature (2021). doi: 10.1038/s41586-021-04049-2. dietary trial in 10 patients. Nutrition (2012) 28(10):1028-35. Epub 2012/07/31. doi: 10.1016/j.nut.2012.05.001. PubMed PMID: 22840388. quality of life in 16 patients with advanced cancer: A pilot trial. Nutr Metab (Lond) (2011) 8(1):54. Epub 2011/07/29. doi: 10.1186/1743-7075-8-54. PubMed PMID: 21794124; PubMed Central PMCID: PMCPMC3157418.

611 37. Rieger J, Bahr O, Maurer GD, Hattingen E, Franz K, Brucker D, et al. ERGO: a pilot study of 612 ketogenic diet in recurrent glioblastoma. Int J Oncol (2014) 44(6):1843-52. Epub 2014/04/15. doi: 613 10.3892/ijo.2014.2382. PubMed PMID: 24728273; PubMed Central PMCID: PMCPMC4063533.

614 38. Goldberg EL, Shchukina I, Asher JL, Sidorov S, Artyomov MN, Dixit VD. Ketogenesis 615 activates metabolically protective gammadelta T cells in visceral adipose tissue. Nat Metab (2020) 616 2(1):50-61. Epub 2020/07/23. doi: 10.1038/s42255-019-0160-6. PubMed PMID: 32694683.

617 39. Newman JC, Covarrubias AJ, Zhao M, Yu X, Gut P, Ng CP, et al. Ketogenic Diet Reduces 618 Midlife Mortality and Improves Memory in Aging Mice. Cell Metab (2017) 26(3):547-57 e8. Epub 
bioRxiv preprint doi: https://doi.org/10.1101/2021.12.19.473355; this version posted December 21, 2021. The copyright holder for this preprint

(which was not certified by peer review) is the author/funder, who has granted bioRxiv a license to display the preprint in perpetuity. It is made

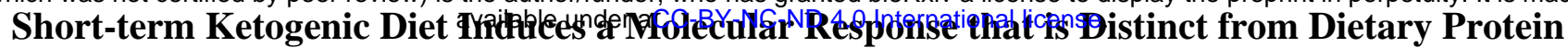
Restriction

619 2017/09/07. doi: 10.1016/j.cmet.2017.08.004. PubMed PMID: 28877458; PubMed Central PMCID: 620 PMCPMC5605815.

621 40. de Groot S, Lugtenberg RT, Cohen D, Welters MJP, Ehsan I, Vreeswijk MPG, et al. Fasting 622 mimicking diet as an adjunct to neoadjuvant chemotherapy for breast cancer in the multicentre

623

624

625 randomized phase 2 DIRECT trial. Nature communications (2020) 11(1):3083. Epub 2020/06/25. doi: 10.1038/s41467-020-16138-3. PubMed PMID: 32576828; PubMed Central PMCID: PMCPMC7311547 L-Nutra. The remaining authors declare no competing interests.

41. Brandhorst S. Fasting and fasting-mimicking diets for chemotherapy augmentation.

627 GeroScience (2021) 43(3):1201-16. Epub 2021/01/08. doi: 10.1007/s11357-020-00317-7. PubMed PMID: 33410090; PubMed Central PMCID: PMCPMC8190229.

629 42. Wei M, Brandhorst S, Shelehchi M, Mirzaei H, Cheng CW, Budniak J, et al. Fasting630 mimicking diet and markers/risk factors for aging, diabetes, cancer, and cardiovascular disease. Sci 631 Transl Med (2017) 9(377). Epub 2017/02/17. doi: 10.1126/scitranslmed.aai8700. PubMed PMID: 632 28202779; PubMed Central PMCID: PMCPMC6816332.

633 43. Brandhorst S, Choi IY, Wei M, Cheng CW, Sedrakyan S, Navarrete G, et al. A Periodic Diet 634 that Mimics Fasting Promotes Multi-System Regeneration, Enhanced Cognitive Performance, and 635 Healthspan. Cell Metab (2015) 22(1):86-99. Epub 2015/06/23. doi: 10.1016/j.cmet.2015.05.012. 636 PubMed PMID: 26094889; PubMed Central PMCID: PMCPMC4509734.

44. Robertson LT, Trevino-Villarreal JH, Mejia P, Grondin Y, Harputlugil E, Hine C, et al. Protein and Calorie Restriction Contribute Additively to Protection from Renal Ischemia Reperfusion Injury Partly via Leptin Reduction in Male Mice. J Nutr (2015) 145(8):1717-27. doi:

640 10.3945/jn.114.199380. PubMed PMID: 26041674; PubMed Central PMCID: PMCPMC4516761.

641 45. Kip P, Trocha KM, Tao M, O'Leary J J, Ruske J, Giulietti JM, et al. Insights From a Short-

642

643 Term Protein-Calorie Restriction Exploratory Trial in Elective Carotid Endarterectomy Patients. Vascular and endovascular surgery (2019) 53(6):470-6. Epub 2019/06/21. doi: 10.1177/1538574419856453. PubMed PMID: 31216949.

645 46. Jongbloed F, de Bruin RWF, Klaassen RA, Beekhof P, van Steeg H, Dor FJMF, et al. Short-

Term Preoperative Calorie and Protein Restriction Is Feasible in Healthy Kidney Donors and Morbidly Obese Patients Scheduled for Surgery. Nutrients (2016) 8(5):306. doi: 10.3390/nu8050306. PubMed PMID: 27213441.

649 47. Rothwell NJ, Stock MJ, Tyzbir RS. Mechanisms of thermogenesis induced by low protein 650 diets. Metabolism (1983) 32(3):257-61. Epub 1983/03/01. doi: 10.1016/0026-0495(83)90190-7. 651 PubMed PMID: 6827996.

652 48. Hill CM, Laeger T, Albarado DC, McDougal DH, Berthoud HR, Munzberg H, et al. Low protein-induced increases in FGF21 drive UCP1-dependent metabolic but not thermoregulatory endpoints. Sci Rep (2017) 7(1):8209. Epub 2017/08/16. doi: 10.1038/s41598-017-07498-w. PubMed PMID: 28811495; PubMed Central PMCID: PMCPMC5557875.

49. Fisher FM, Maratos-Flier E. Understanding the Physiology of FGF21. Annu Rev Physiol (2016) 78:223-41. Epub 2015/12/15. doi: 10.1146/annurev-physiol-021115-105339. PubMed PMID: 65826654352.

659 50. Geng L, Lam KSL, Xu A. The therapeutic potential of FGF21 in metabolic diseases: from 660 bench to clinic. Nat Rev Endocrinol (2020) 16(11):654-67. Epub 2020/08/09. doi: 10.1038/s41574661 020-0386-0. PubMed PMID: 32764725. 


\section{Restriction}

662 51. Paoli A, Rubini A, Volek JS, Grimaldi KA. Beyond weight loss: a review of the therapeutic 663 uses of very-low-carbohydrate (ketogenic) diets. Eur J Clin Nutr (2013) 67(8):789-96. Epub 664 2013/06/27. doi: 10.1038/ejcn.2013.116. PubMed PMID: 23801097; PubMed Central PMCID: 665 PMCPMC3826507.

666 52. Yu G, Wang LG, Han Y, He QY. clusterProfiler: an R package for comparing biological 667 themes among gene clusters. Omics : a journal of integrative biology (2012) 16(5):284-7. Epub 668 2012/03/30. doi: 10.1089/omi.2011.0118. PubMed PMID: 22455463; PubMed Central PMCID: 669 PMCPMC3339379.

670 53. Langfelder P, Horvath S. WGCNA: an R package for weighted correlation network analysis. BMC bioinformatics (2008) 9:559. Epub 2008/12/31. doi: 10.1186/1471-2105-9-559. PubMed PMID: 19114008; PubMed Central PMCID: PMCPMC2631488.

673 54. Gearing LJ, Cumming HE, Chapman R, Finkel AM, Woodhouse IB, Luu K, et al. CiiiDER: A tool for predicting and analysing transcription factor binding sites. PloS one (2019) 14(9):e0215495. Epub 2019/09/05. doi: 10.1371/journal.pone.0215495. PubMed PMID: 31483836; PubMed Central PMCID: PMCPMC6726224.

55. Badman MK, Kennedy AR, Adams AC, Pissios P, Maratos-Flier E. A very low carbohydrate ketogenic diet improves glucose tolerance in ob/ob mice independently of weight loss. Am J Physiol Endocrinol Metab (2009) 297(5):E1197-204. Epub 2009/09/10. doi: 10.1152/ajpendo.00357.2009. PubMed PMID: 19738035; PubMed Central PMCID: PMCPMC2781352. the Nutritional and Metabolic Context of FGF21 Using the Geometric Framework. Cell Metab (2016) 24(4):555-65. Epub 2016/10/04. doi: 10.1016/j.cmet.2016.09.001. PubMed PMID: 27693377.

57. Hill CM, Laeger T, Dehner M, Albarado DC, Clarke B, Wanders D, et al. FGF21 Signals PubMed Central PMCID: PMCPMC6579533.

688 58. Wu Y, Li B, Li L, Mitchell SE, Green CL, D'Agostino G, et al. Very-low-protein diets lead to reduced food intake and weight loss, linked to inhibition of hypothalamic mTOR signaling, in mice. Cell Metab (2021) 33(5):888-904 e6. Epub 2021/03/06. doi: 10.1016/j.cmet.2021.01.017. PubMed PMID: 33667386.

692 59. Cota D, Proulx K, Smith KA, Kozma SC, Thomas G, Woods SC, et al. Hypothalamic mTOR 693 signaling regulates food intake. Science (New York, NY) (2006) 312(5775):927-30. Epub 2006/05/13. 694 doi: 10.1126/science.1124147. PubMed PMID: 16690869. 
bioRxiv preprint doi: https://doi.org/10.1101/2021.12.19.473355; this version posted December 21, 2021. The copyright holder for this preprint (which was not certified by peer review) is the author/funder, who has granted bioRxiv a license to display the preprint in perpetuity. It is made

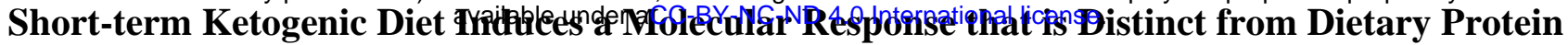
Restriction

$701 \quad 11 \quad$ Supplementary Figures

702

A

\begin{tabular}{|c|c|c|c|c|}
\hline Diet & \% Fat & \% Carbs & \% Protein & Energy (kcal/g) \\
\hline CTL & $\mathbf{1 0}$ & $\mathbf{7 0}$ & $\mathbf{2 0}$ & $\mathbf{1 . 9}$ \\
\hline PF & $\mathbf{1 0}$ & $\mathbf{9 0}$ & $\mathbf{0}$ & $\mathbf{1 . 9}$ \\
\hline KD0P & $\mathbf{9 0}$ & $\mathbf{1 0}$ & $\mathbf{0}$ & $\mathbf{3 . 0}$ \\
\hline KD5P & $\mathbf{9 0}$ & $\mathbf{5}$ & $\mathbf{5}$ & $\mathbf{3 . 0}$ \\
\hline KD10P & $\mathbf{9 0}$ & $\mathbf{0}$ & $\mathbf{1 0}$ & $\mathbf{3 . 0}$ \\
\hline KD20P & $\mathbf{8 0}$ & $\mathbf{0}$ & $\mathbf{2 0}$ & $\mathbf{2 . 7}$ \\
\hline
\end{tabular}

B

\begin{tabular}{|c|c|c|c|c|c|c|c|}
\hline Diet & D12450BSpx & D10070801Lpx & Cocoa Butter & Casein & Sucrose & Water & Agar \\
\hline CTL & 205 & 0 & 0 & 45 & 0 & 250 & 5 \\
\hline PF & 205 & 0 & 0 & 0 & 45 & 250 & 5 \\
\hline KD0P & 0 & 51.5 & 158.8 & 0 & 39.7 & 281.3 & 5.6 \\
\hline KD5P & 0 & 51.5 & 158.8 & 19.9 & 19.9 & 281.7 & 5.6 \\
\hline KD10P & 0 & 51.5 & 158.8 & 39.7 & 0 & 282.1 & 5.6 \\
\hline KD20P & 0 & 51.5 & 127 & 71.5 & 0 & 282.1 & 5.6 \\
\hline
\end{tabular}

$\mathrm{C}$

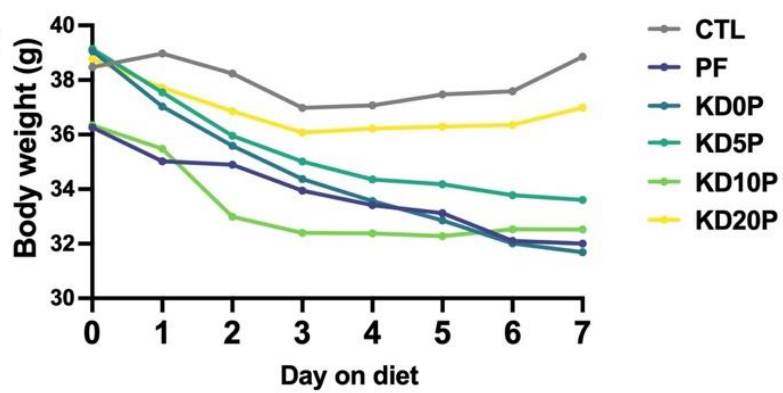

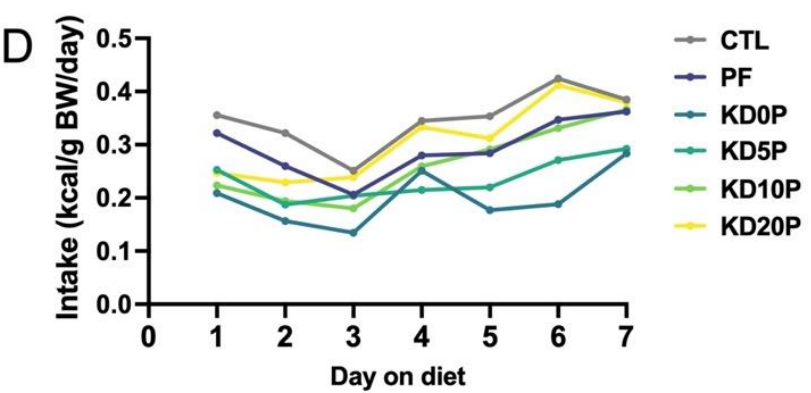

704 Supplementary Figure 1. (A) Table of macronutrient compositions and energy densities of the experimental diets. (B) Table of ingredients in experimental diets in grams. (C) Body weights in grams across 7 days of feeding experiments diets. (D) Energy intakes in kcals per gram body weight per day across 7 days of feeding experimental diets. Intake was normalized to the summed body weight of 2 mice co-housed per cage and presented per cage. 
bioRxiv preprint doi: https://doi.org/10.1101/2021.12.19.473355; this version posted December 21, 2021. The copyright holder for this preprint (which was not certified by peer review) is the author/funder, who has granted bioRxiv a license to display the preprint in perpetuity. It is made

Short-term Ketogenic Diet TYrithees Restriction
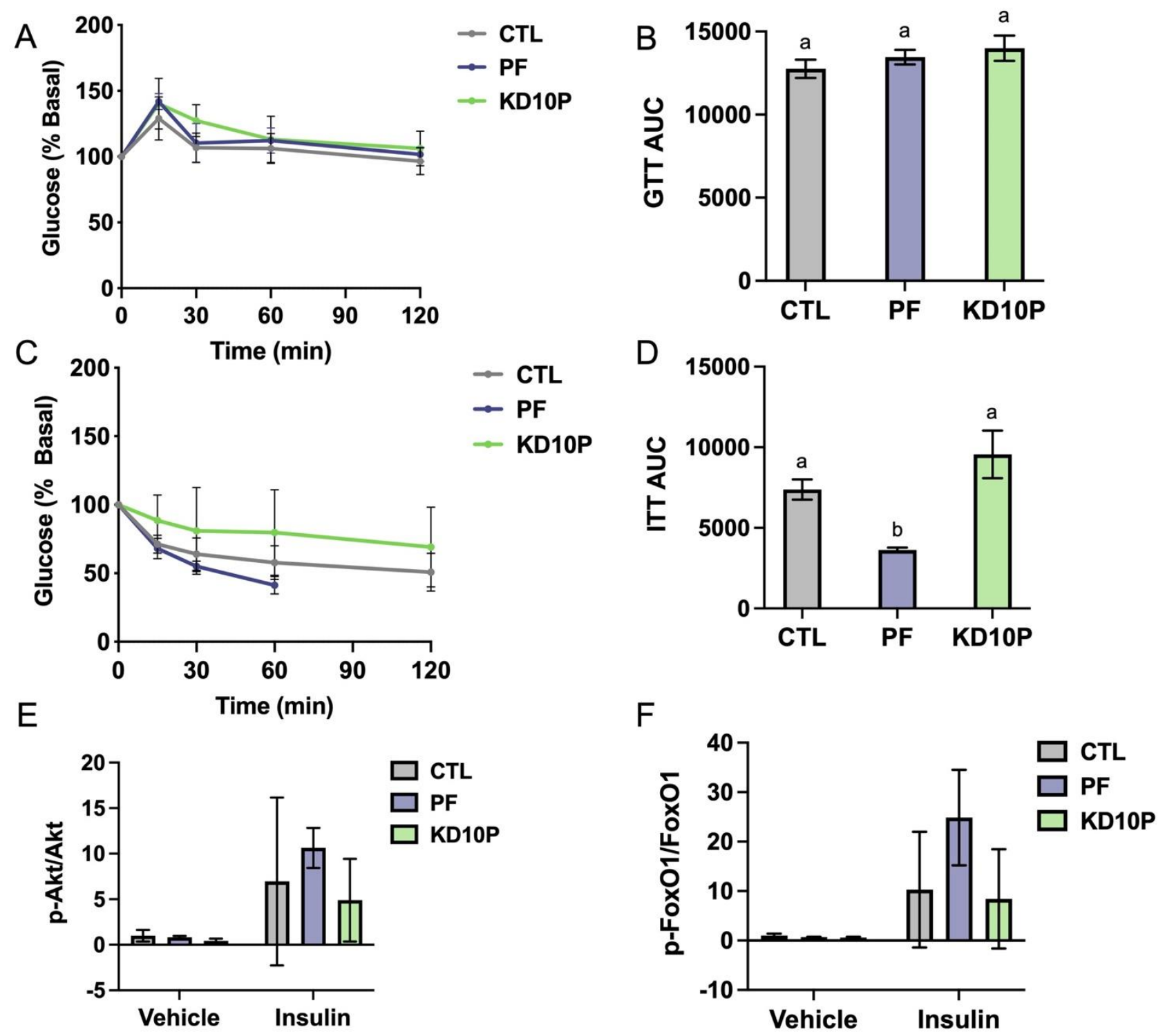

710 Supplementary Figure 2. (A) Blood glucose levels during oral glucose tolerance test, normalized to baseline and (B) corresponding area under the curve (AUC). (C) Blood glucose levels during insulin tolerance test normalized to baseline and (D) corresponding AUC. (E) Quantification of phosphoAKT normalized to total AKT by western blot. (F) Quantification of phospho-FoxO1 normalized to total FoxO1 by western blot. 
bioRxiv preprint doi: https://doi.org/10.1101/2021.12.19.473355; this version posted December 21, 2021. The copyright holder for this preprint (which was not certified by peer review) is the author/funder, who has granted bioRxiv a license to display the preprint in perpetuity. It is made

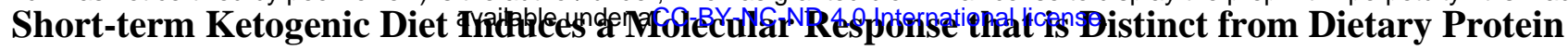
Restriction

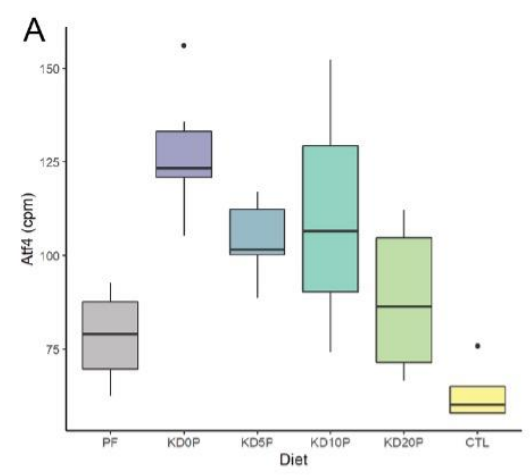

D

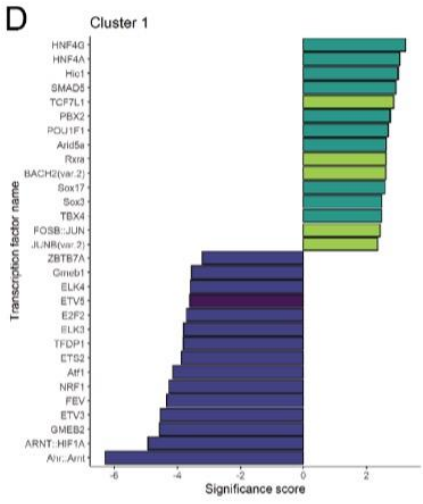

G

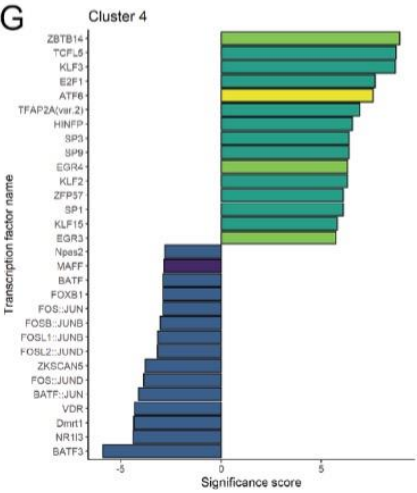

B

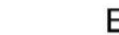

E
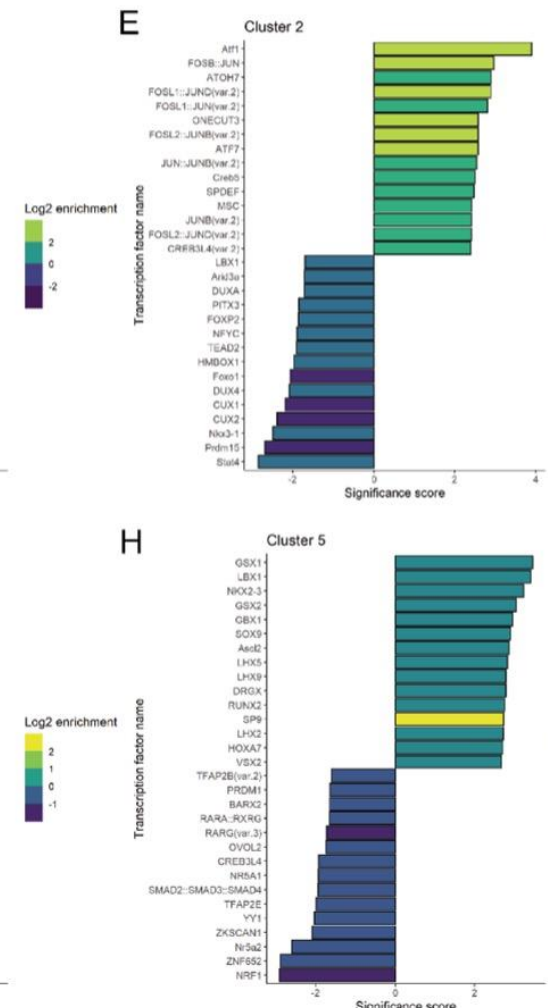

$\mathrm{H}$

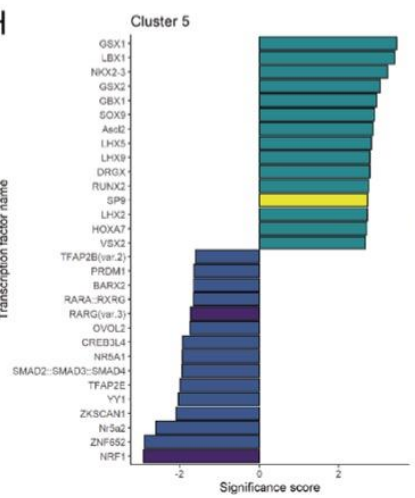

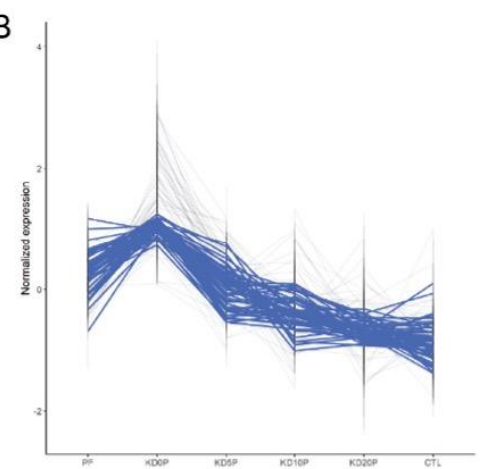

$\mathrm{F}$
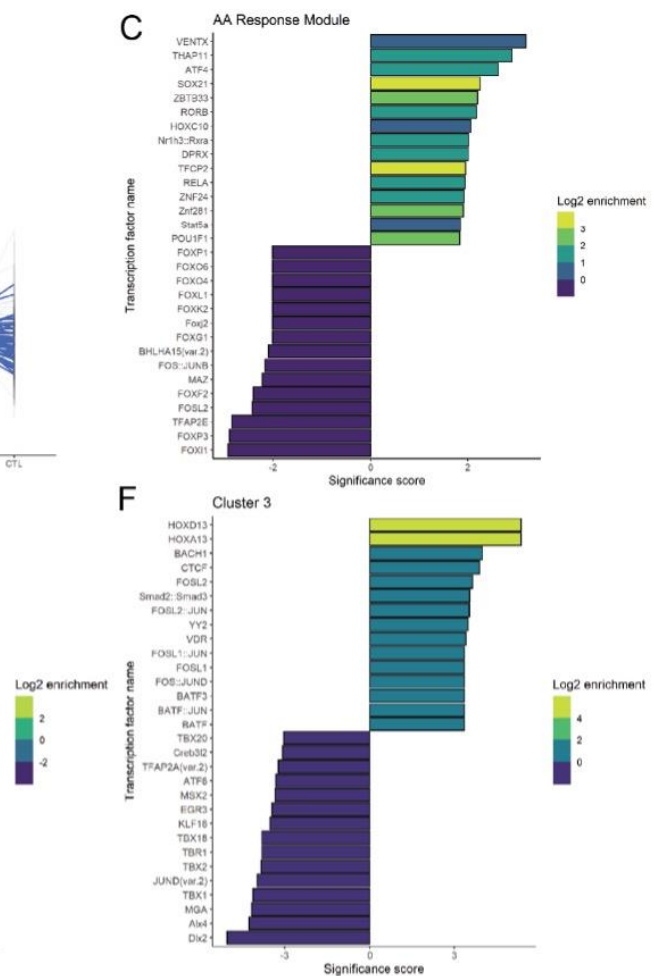

Cluster 3

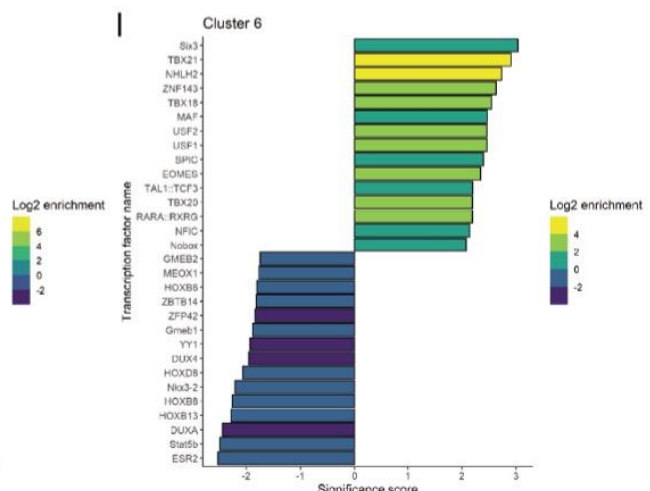

716 Supplementary Figure 3. (A) Hepatic Atf4 transcript levels as counts per million (cpm) across experimental diets. (B) Weighted gene correlation network analysis module containing amino acid responsive genes including Psat1, Asns and Fgf21. (C) Top 10 enriched and depleted transcription factor binding motifs corresponding to the module in B. (D-I) Top 10 enriched and depleted transcription factor binding motifs in clusters 1 through 6 . 


\section{D12450BS and D12450BSpx}

\section{Water Suspendible Rodent Diet With $10 \mathrm{kcal} \%$ Fat and Same without Added Protein}

\begin{tabular}{|c|c|c|c|c|}
\hline Product \# & \multicolumn{2}{|c|}{ D12450BS } & \multicolumn{2}{|c|}{ D12450BSpx } \\
\hline & $\mathrm{gm}$ & kcal & $\mathrm{gm}$ & $\mathrm{kcal}$ \\
\hline Protein & 19.2 & 20.0 & 0.0 & 0.0 \\
\hline Carbohydrate & 67.3 & 70.0 & 83.3 & 87.5 \\
\hline Fat & 4.3 & 10.0 & 5.3 & 12.5 \\
\hline Total & & 100.0 & & 100.0 \\
\hline $\mathrm{kcal} / \mathrm{gm}$ & 3.85 & & 3.81 & \\
\hline Ingredient & gm & kcal & gm & kcal \\
\hline Casein, 80 Mesh & 0 & 0 & 0 & 0 \\
\hline Casein, Enzyme Hydrolyzed & 200 & 800 & 0 & 0 \\
\hline L-Cystine & 3 & 12 & 0 & 0 \\
\hline Sucrose & 350 & 1400 & 350 & 1400 \\
\hline Maltodextrin 42 & 350 & 1400 & 350 & 1400 \\
\hline Cellulose, BW200 & 40 & 0 & 40 & 0 \\
\hline Xanthan Gum & 10 & 0 & 10 & 0 \\
\hline Soybean Oil & 25 & 225 & 25 & 225 \\
\hline Lard & 20 & 180 & 20 & 180 \\
\hline Mineral Mix S10011 & 0 & 0 & 0 & 0 \\
\hline Mineral Mix S10026 & 10 & 0 & 10 & 0 \\
\hline DiCalcium Phosphate & 13 & 0 & 13 & 0 \\
\hline Calcium Carbonate & 5.5 & 0 & 5.5 & 0 \\
\hline Potassium Citrate, $1 \mathrm{H} 2 \mathrm{O}$ & 16.5 & 0 & 16.5 & 0 \\
\hline Vitamin Mix V10001 & 10 & 40 & 10 & 40 \\
\hline Choline Bitartrate & 2 & 0 & 2 & 0 \\
\hline FD\&C Yellow Dye \#5 & 0.05 & 0 & 0.05 & 0 \\
\hline Total & 1055.05 & 4057 & 852.05 & 3245 \\
\hline
\end{tabular}




\section{Restriction}

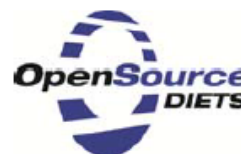

\section{D10070801L And D10070801Lpx}

\section{Water Suspendible Rodent Diet With}

90 kcal\% Fat (Mostly Cocoa Butter)

\begin{tabular}{|c|c|c|c|c|c|c|}
\hline \multirow[t]{2}{*}{ Product \# } & \multicolumn{2}{|c|}{ D10070801 } & \multicolumn{2}{|c|}{ D10070801L } & \multicolumn{2}{|c|}{ D10070801Lpx } \\
\hline & gm\% & kcal\% & $\mathrm{gm} \%$ & kcal\% & $\mathrm{gm} \%$ & kcal\% \\
\hline Protein & 17 & 10 & 17 & 10 & 0 & 0 \\
\hline Carbohydrate & 0 & 0 & 0 & 0 & 0 & 0 \\
\hline Fat & 67 & 90 & 67 & 90 & 20 & 100 \\
\hline Total & & 100 & & 100 & & 100 \\
\hline kcal/gm & 6.7 & & 6.7 & & 1.8 & \\
\hline & & & & & & \\
\hline Ingredient & gm & kcal & gm & kcal & gm & kcal \\
\hline Casein & 100 & 400 & 100 & 400 & 0 & 0 \\
\hline L-Cystine & 1.5 & 6 & 1.5 & 6 & 0 & 0 \\
\hline & & & & & & \\
\hline Corn Starch & 0 & 0 & 0 & 0 & 0 & 0 \\
\hline Maltodextrin 10 & 0 & 0 & 0 & 0 & 0 & 0 \\
\hline Sucrose & 0 & 0 & 0 & 0 & 0 & 0 \\
\hline & & & & & & \\
\hline Cellulose, BW200 & 50 & 0 & 40 & 0 & 40 & 0 \\
\hline Xanthan Gum & 0 & 0 & 10 & 0 & 10 & 0 \\
\hline & & & & & & \\
\hline Soybean Oil & 25 & 225 & 25 & 225 & 25 & 225 \\
\hline Lard & 0 & 0 & 0 & 0 & 0 & 0 \\
\hline Cocoa Butter & 381 & 3429 & 381 & 3429 & 0 & 0 \\
\hline Primex & 0 & 0 & 0 & 0 & 0 & 0 \\
\hline & & & & & & \\
\hline Mineral Mix, S10026 & 10 & 0 & 10 & 0 & 10 & 0 \\
\hline DiCalcium Phosphate & 13 & 0 & 13 & 0 & 13 & 0 \\
\hline Calcium Carbonate & 5.5 & 0 & 5.5 & 0 & 5.5 & 0 \\
\hline Potassium Citrate, $1 \mathrm{H} 2 \mathrm{O}$ & 16.5 & 0 & 16.5 & 0 & 16.5 & 0 \\
\hline & & & & & & \\
\hline Vitamin Mix, V10001 & 0 & 0 & 0 & 0 & 0 & 0 \\
\hline Vitamin Mix, V10001C,10x vitamins & 1 & 0 & 1 & 0 & 1 & 0 \\
\hline Choline Bitartrate & 2 & 0 & 2 & 0 & 2 & 0 \\
\hline & & & & & & \\
\hline Cholesterol & 0 & 0 & 0 & 0 & 0 & 0 \\
\hline Sodium Cholic Acid & 0 & 0 & 0 & 0 & 0 & 0 \\
\hline & & & & & & \\
\hline FD\&C Yellow Dye \#5 & 0.025 & 0 & 0.025 & 0 & 0.025 & 0 \\
\hline FD\&C Red Dye \#40 & 0.025 & 0 & 0.025 & 0 & 0.025 & 0 \\
\hline FD\&C Blue Dye \#1 & 0 & 0 & 0 & 0 & 0 & 0 \\
\hline Total & 605.55 & 4060 & 605.55 & 4060 & 123.05 & 225 \\
\hline
\end{tabular}

